\title{
Tieion Akropolisi
}

\author{
Şahin Yıldırım*
}

\begin{abstract}
$\ddot{O}_{z}$
Tieion antik kenti, Karadeniz kıyısının batı kesiminde, Kimi antik çağ yazarları tarafindan Bithynia ile Paphlagonia arasında sinır olarak kabul edilen Billaos nehrinin (Filyos) hemen yakınında yer almaktadır. Yerleşim, antik ve modern kaynaklar tarafindan MÖ 7. yüzyllın ikinci yarısında, Tios adında Miletoslu bir rahibin önderliğinde kurulmuş bir Miletos kolonisi olarak nitelendirilmektedir. Tieion Akropolisinde kazılar sonucunda ortaya çıkarılan MÖ 7. ve 6. yüzyllara tarihlendirilen İonia seramikleri, yerleşimin Miletos tarafindan kurulduğunu doğrulamaktadır. Bununla birlikte önemli bir liman kenti olan Tieion, Karadeniz'in ticaret yolları üzerinde, balıkçlık, şarap üretimi ve tahıl yetiştiriciliğinin ön plana çıktığı bir yerdi. Antik limanın mendirekleri, akropolisteki tapınağı, hamamları, su kemerleri ve tiyatrosuyla Tieion, tipik bir Roma kenti görünümündedir.

Yukarı şehir çevresinde son yıllarda yürütülen kazı çalışmalarında kentin kuruluş dönemlerine ait yapı kalıntılarına rastlanmıştı. Bu yapılar dikdörtgen ya da yuvarlak şekilde açılmış bir çukurun içinde iptidai şekilde inşa edilmiş konutlardan oluşmaktadır. $\mathrm{Bu}$ konutların içlerinde ve çevrelerinde yapılan çalışmalarda, MÖ 7. yüzyılın son çeyreğine tarihlendirilen, Miletos yapımı Orta Yaban Keçisi II evresi olarak tanımlanan seramik parçaları bulunmuştur. Bu seramik gurubu ile aynı tabakalarda yerel olarak üretilmiş Phryg menşeili koyu gri, siyah ve kahverengi astarlı seramikler de ortaya çıkarılmıştır. Akropoldeki P1 konutunda ise Grek Koloni Çağı tabakalarının hemen altında, olasılıkla Attika Geç Geometrik Dönemi’ne tarihlendirilen pişmiş toprak bir at heykelciği parçası ile karşılaşılmıştı. Bir diğer at figürini parçası da aynı konutta başka bir lokasyonda bulunmuştur ancak, bu ikinci örnek gerek kil yapısı gerekse de stil bakımından yerel üretim olarak değerlendirilmiştir. Ayrıca bu figürinlerle birlikte çok
\end{abstract}

* Doç. Dr., Bartın Üniversitesi, Arkeoloji Uygulama ve Araştırma Merkezi Müdürlügü̈, Bartı/ TÜRKIYE, sahinyildirim@bartin.edu.tr ORCID: 0000-0002-5887-075X DOI: $10.37879 /$ belleten.2021.383 Makale Gönderim Tarihi: 27.02.2020 - Makale Kabul Tarihi: 05.04.2021 
sayıda yerel imalat çanak çömlek de ortaya çıkarılmıştır. Böylece, Güney Karadeniz'de Grek Koloni Çağı ve Koloni Çağı öncesine dair somut kanıtlar ilk defa elde edilmiştir.

Anahtar Kelimeler: Karadeniz, Grek Kolonizasyonu, Frig, Akropolis, Oikist.

\title{
The Acropolis of Tieion
}

\begin{abstract}
The ancient city of Tieion is located on the western region of the Southern Black Sea littoral, next to the Billaos river (Filyos) which was considered as the border between Bithynia and Paphlagonia. It is known as a Milesean colony, which was founded in the second half of the seventh century BC. It is believed that this colony was founded by a priest called Tios in the $7^{\text {th }}$ century BC. Ionian pottery, excavated on the acropolis of Tieion, dated to the $7^{\text {th }} / 6^{\text {th }}$ Century BC confirms the written sources that Miletus was the founder of the city. As a harbour city Tieion was situated on the sea route of the Black Sea trading with fish, wine and grain. Tieion looks like a typical Roman city with the breakwater of the ancient harbor, the temple in the acropolis, baths, aqueducts and theater.

As a result of the recent archaeological excavations carried out in the vicinity of the acropolis, the ruins of various buildings belonging to the foundation periods of the city were encountered. These structures which were formed by the underground pits that have meshed stone masonry within, constitutes round, oval and rectangular forms. During the studies conducted in and around these structures; the Middle Wild Goat II style ceramics which dating to the last quarter of the 7 th century $\mathrm{BC}$ and the local productions in dark gray, black and brown wares some of which handmade were also uncovered. Therewithal in the archaeological strata located just below the colonial levels, the terracotta horse figurine fragments dated to the Late Geometric Period and a large amount of local pottery samples were obtained. Thus, the concrete evidences on Greek Colonization of the Southern Black Sea have been acquired.
\end{abstract}

Keywords: Black Sea, Greek Colonization, Phryg, Acropolis, Oikist.

\section{Giriş}

Günümüzde Zonguldak İli, Filyos Beldesi sınırları içerisinde bulunan Tios ya da bir diğer adıyla Tieion antik kenti Amasyalı Strabon (Geographika, XII, 3.5) tarafindan "Söylenecek çok önemli bir şeyi olmayan kent." olarak ifade edilmekteydi. Strabon'un önemsiz bir kent olarak andığı bu yerleşim, günümüzde Türkiye'nin 
Karadeniz kıyısında yer alıp da üzerinde modern yerleşimin bulunmadığı, yerleşim sınırlarının çok önemli ölçüde korunduğu neredeyse tek antik kent durumundadır. Aynı zamanda Güney Karadeniz sahilinde bilimsel arkeolojik kazısı uzun yıllardır sürdürülen nadir örneklerdendir. Bu bakımdan burada yürütülen kazılarda ortaya çıkarılan arkeolojik veriler, Karadeniz arkeolojisi açısından çok büyük önem taşımaktadır.

Tieion ile ilgili olarak Antik Çă̆ yazarlarından Marcianus (Geographus, 8), kentin hemen doğusunda Karadeniz'e dökülen Billaios Irmağı'nın Bithynia ile Paphlagonia bölgeleri arasında sınır teşkil ettiğini ve kentin Billaios, (Filyos) Irmağı'nın yakınında, Karadeniz'e uzanan bir yarımadanın üzerinde kurulduğunu aktarmaktadır (Fig. 1). Yaşı Plinius (Naturalis Historia, VI. 2.5) da Marcianus gibi Paphlagonia'nın batı sınırının Billaios Irmağı ile birlikte başladığını ifade etmektedir. Yine bir diğer antik dönem yazarı olan Arrianus (Periplus Ponti Euxini, XIII, 5, 5) Tieion ile Billaios Irmağı arasında 20 stadia kadar bir mesafe bulunduğunu söyler.

Kentin kuruluşu ile ilgili başvuru kaynaklarımız antik yazarlardır. Strabon (Geographika, XII, 3.5), Koloni Çağı öncesinde Parthenios Nehri'ne kadar olan bölgede Kaukonlar adında bir kavmin yaşadığını belirtmektedir. Bizanslı yazar Eustathius (Eust. Ad II. II 855) ise, Paphlagon kökenli Kaukonların başkentinin Tieion olduğunu aktarmaktadır ${ }^{1}$. Hem antik ve hem de modern kaynaklar kentin Miletos'dan gelen kolonistlerce kurulduğu konusunda neredeyse hemfikirdirler².

1 Bülent Öztürk, "The History of Tieion/Tios (Eastern Bithynia) in the light of Inscriptions", (ed.) Manoledakis, M. Exploring the Hospitable Sea (Proceedings of the International Workshop on the Black Sea in Antiquity held in in Thessaloniki, 21-23 September 2012), (BAR International Series 2498), Oxford (2013a), s. 147.

2 Sümer, Atasoy, "Zonguldak - Fiyos (Tios/Tieion/Tios/Tianos/Tieum) Kurtarma Kazısı", (ed.) İ. Delemen, Prof. Dr. Haluk Abbasoğlu'na 65. Yaş Armağanı, Istanbul (2008), s. 91; Sümer Atasoy, "Önsöz/ Forward", (ed.) S. Atasoy ve Ş. Yıldırım, Tios-Filyos Arkeolojik Kazı Projesi. Zonguldak'ta Bir Antik Kent TIOS, Ankara (2015a)s. 1-13; George Bean, "Tios", The Princeton Encyclopedia of Classical Sites, Princeton (1979), s. 925; James Crow-Stephen Hill, "The Byzantine Fortifications of Amastris in Paphlagonia", Anatolian Studies 45, (1995), s. 251; Izzet Esen, "Antik Tios/Tieion/Villaios(Filyos) Kenti”, Anadolu Medeniyetleri Müzesi 2002 Yillğ̆, Ankara (2003), s. 197; Christian Marek, Pontus et Bithynia: Die römischen Provinzen im Norden Kleinasiens, Mainz, 2003, s. 609; Bülent Öztürk-F. İhsan Sönmez, "Batı Karadeniz'de Bir Antik Kent Kazısı: Tios (Filyos)/ Tios (Filyos): Excavations at an ancient city on the western Black Sea Region of Turkey", Arkeoloji Sanat 127, (2008), s. 134; Bülent Öztürk, "Kuruluşundan Bizans Devri Sonuna Kadar Tios Antik Kenti/The ancient city of Tios from its establishment till the end of the Byzantine Period", Arkeoloji Sanat 128, (2008), s. 63-65; Bülent Öztürk, Küçükasya’nın Batı Karadeniz Kiyısında Bir Antik Kent: Tios (Tieion), Marmara University, (Ph. D Dissertation), Istanbul, 2012; Bülent Öztürk, "The 
Tieion'un Miletos tarafindan kurulmuş bir Grek koloni kenti olduğuyla ilgili başvuru kaynaklarından birisi de Athenaios'tur. Athenaios(Deipnosophistai VIII, 331), Fosil balığı adı verilen bir tür balığın hem Heracleia'da hem de Tieion'da üretildiğinden bahseder. Kentin Miletos kökenine atıfta bulunan diğer bir kaynak da Arrianus'dur. Arrianus (Periplus Ponti Euxini, XIII, 5, 5), Tieion hakkında "İon menşeili bir Grek kenti" tabirini kullanmıştır. Arrianus da bu yerleşimi, "Miletoslular'n bir kolonisi" olarak nitelendirmektedir". Kentin başlarında Tios adında bir rahip bulunan Miletoslular tarafindan kurulduğu ifadesi birçok kaynakta karşımıza çıar4. Stephanos Byzantinos, (Steph. Byz. 624, 20.) Herennius Philon'un Ethnika adlı eserinden aktararak kentin kurucusunun Miletoslu rahip Tios olduğunu belirtir. Rahip Tios, kentin özellikle Roma Dönemi'ne tarihlendirilen otonom sikkelerinde tasvir edilmiş ve kent açısından taşıdığı önem böylelikle ifade edilmiştir.

Tieion'un bir Miletos kolonisi olduğunu gösteren arkeolojik veriler ise antik kentin akropolisinde yürütülen kazılar sırasında ortaya çıkarılmıştır. MÖ 7. ve 6 . yüzyıllara tarihlendirilen Arkaik Dönem siyah ve kırmızı figür Attika seramikleri ile yine aynı dönemlere tarihlendirilen İonia menşeili seramikler, Tieion'un kurucu kenti olan Miletos'la bağlantılarını gözler önüne sermektedir ${ }^{5}$. Yazının ilerleyen bölümlerinde akropolde bulunan seramikler üzerinde daha ayrıntılı bir şekilde durulacaktır.

History of Tieion/Tios (Eastern Bithynia) in the light of Inscriptions", (ed.) Manoledakis, $M$. Exploring the Hospitable Sea (Proceedings of the International Workshop on the Black Sea in Antiquity held in in Thessaloniki, 21-23 September 2012), (BAR International Series 2498), Oxford (2013a), s. 147; A. H. Martin Jones, The Cities of the Eastern Roman Provinces, 2nd ed., Amsterdam, 1983; Walther Ruge, "Tieion”, RE VI A.1, (1936), s. 856; Louis Robert, Études Anatoliennes: Recherches sur les inscriptions grecques de l'Asie Mineur, Paris, 1937, s. 270; Şahin Yıldırım, "Tios Roma Tiyatrosu/ The Roman Theater of Tios". (ed.) S. Atasoy ve Ş. Yıldırım, Tios-Filyos Arkeolojik Kazı Projesi. Zonguldak'ta Bir Antik Kent TIOS, Ankara (2015), s. 271; Şahin Yıldırım, "Tios-Tieion: Söylenecek Çok Önemli Bir Şeyi Olmayan Kent”, Trakya Üniversitesi Edebiyat Fakültesi Dergisi 7/14, (2017a), s. 210.

3 Öztürk, "Kuruluşundan Bizans", s. 64.

4 Marek, Pontus et Bithynia, s. 16; Atasoy "Zonguldak - Fiyos", s. 91; Öztürk, "Kuruluşundan Bizans" s. 64.

5 Sümer Atasoy - Şahin Yıldırım, "Filyos-Tios 2009 Yılı Kazısı", KST XXXII/IV, 2011 (Ankara), s. 2; Sümer Atasoy - Hüseyin Erpehlivan, "Tios'da Erken Yerleşmeye Ait Keramikler/ Ceramics from the Early Settlement at Tios", (ed.) S. Atasoy ve Ş. Yıldırım, Tios-Filyos Arkeolojik Kazı Projesi. Zonguldak'ta Bir Antik Kent TIOS, Ankara (2015), s. 202-203; Şahin Yıldırım, "Tios-Tieion 2015 Yılı Kazı Çalışmaları", KST XXXVIII/I, Ankara (2017b), s. 465-478. 
Kent, tıpkı Karadeniz'deki birçok Koloni Çă̆ı yerleşimi gibi, doğal bir limana sahip bir yarımadanın hemen bitişiğinde kurulmuş̧ur. Bununla birlikte iç bölgelerle gerçekleştirilen ticari ilişkilerin yürütülmesini sağlayan Billaios gibi çok önemli bir suyolu da kent limanının doğusunda bulunmakta ve Karadeniz'e bir delta oluşturarak dökülmektedir. Billaios Irmağı, günümüzde kullanılan adıyla Filyos Nehri, Kreteia/Flaviopolis yakınlarında doğmaktadır (Fig. 2) ${ }^{6}$. Nehrin doğduğu yerden, denize döküldüğü yere kadar olan toplam uzunluğu 228 km.dir? . İç bölgelerle gerçekleştirilen ticari faaliyetler açısından Karadeniz'e dökülen nehirler çok büyük önem taşımaktadır. Karadeniz'deki nehirlerin sistematik bir şekilde ticari suyolu olarak kullanılmasının temelinde Grek koloni hareketleri yer almaktaydı. Karadeniz boyunca kurulan kentlerin çok önemli bir bölümü iç bölgelerle iletişimin daha kolay sağlandığı nehir ya da akarsu vadilerinin denize kavuştuğu, korunaklı doğal limanlara sahip, jeopolitik açıdan stratejik olan noktalarda kurulmuşlardır. Güney Karadeniz kentlerinin önemli bir bölümünde nehir ticareti ayrıcalıklı bir yere sahiptir. Sangarios, Billaios, Parthenios, Halys, Iris gibi büyük nehirlerle birlikte bazı küçük akarsularıda belirli mevsimlerde taşıma amacıyla kullanılmışır. Ancak bunlardan sadece Tieion'un hemen yakınında, Karadeniz'e dökülen Billaios Nehri üzerinde Roma Dönemi’nde nehir ticareti yürütüldüğünü kanıtlayan mimari izler ve arkeolojik kalıntılar bulunmuştur'.

Tieion antik kenti, aşağı ve yukarı şehir olmak üzere iki ayrı bölümden oluşmaktadır. Kent topoğrafyasında hâkim bir tepe şeklinde olan akropolis, kentin kuruluş dönemine ait tabakaları içinde barındırır. Arkeolojik verilere göre kent ilk olarak burada kurulmuş ve zamanla genişleyerek yaklaşık 60 hektarlık bir alana yayılmıştır. Aşağı şehirde ise ağırıklı olarak Roma İmparatorluk ve Bizans Dönemi yapıları yer almaktadır. Bu yapılar arasında sahil surları, biri antik liman yakınında, diğeri de agora yakınlarında olmak üzere iki hamam yapısı, su kemeri, tiyatro, tapınak terası, kilise kalıntıları, bazilika, yol kalıntıları, tonozlu galeri, sarnıç, antik liman ve mendirekleri yer almaktadır?.

6 Öztürk, Kǚ̧ükasya’nın Batı Karadeniz, s. 96; Robert, Études Anatoliennes, s. 180; Serhat Küçükali, "Forecasting the river discharge, thermal and sediment load characteristics: A case study", (ed.) M. S. Altinakar ve diğerleri, River Flow 2008 (Proceedings of the International Conference on Fluvial Hydraulics, Çeşme, Izmir, Iurkey, 3-5 September 2008), Ankara (2008), s. 1975-1981.

7 İsmail Büyüksalih-Hakan Akçın, Güneş U. Sefercik-Serkan Karakış-A. Murat Marangoz,"Batı Karadeniz Sahil Bölgesindeki Filyos Nehri ve Deltasındaki Değişimlerin Zamansal CBS İle İncelenmesi”, Ege Coğrafi Bilgi Sistemleri Çalıstayn, İzmir (2005), s. 2.

8 Yıldırım, "Söylenecek Çok Önemli”, s. 210-213.

9 Atasoy, "Önsöz/ Forward”; Yıldırım, "Söylenecek Çok Önemli”, s. 219-224. 


\section{Akropolis}

Kentin akropolisi durumunda olan yukarı şehir, doğu batı doğrultusunda yaklaşık 400m. kadar uzanmakta, bazı bölümlerinde daha dar olmakla birlikte yaklaşı $100 \mathrm{~m}$. genişlikte bir yarımadadır. Bu yarımada, batıdan doğuya doğru $30 \mathrm{~m}$. yükseklikten başlayarak, $75 \mathrm{~m}$. yüksekliğe kadar kademeli bir şekilde tırmanan dört ayrı terastan meydana gelmiştir ${ }^{10}$. Kentin kuruluş dönemiyle ilgili arkeolojik veriler, özellikle birinci teras olarak adlandırılan akropolün doğusunda bulunan terasda yoğunlaşmıştır (Fig. 3). Bu bölgede 2006 yllından bu yana yürütülen arkeolojik kazılar, MÖ 7. ve 6. yüzyıllararasına tarihlendirilen arkeolojik kalıntıların ortaya çıkarılmasını sağlamıştır.

En erken evresi MÖ 7. yüzyllın son çeyreğine tarihlendirilen mimari kalıntılar, Koloni Çağı yerleşiminin akropolle sınılı olduğunu göstermektedir. Akropol birinci terasta Geç Klasik Dönem'den itibaren yapılaşma yoğunlaşmaya başlar. Eldeki veriler, kentin özellikle Hellenistik Dönem'den başlayarak büyümeye ve genişlemeye başladığını göstermektedir. Roma Dönemi’nde ise bu büyüme doruk noktasına ulaşır. Gerek mimari gerekse de diğer arkeolojik veriler, Geç Arkaik Dönem'den itibaren akropol ve çevresinin işlev değişikliğine uğradığını, tepenin askeri ve sivil amaçlı kullanımının MÖ 4. yüzyılın sonlarından itibaren terk edilerek yerini dinsel işlevli yapılara bıraktığını göstermektedir. Akropolün hemen her yerinde karşımıza çıkan dini mimariye ait yapı elemanları, sunu kapları ve pişmiş toprak figürünler, akropol ikinci terasın Arkaik Dönem'den Roma Dönemi’nin sonlarına kadar dini hüviyette bir kullanıma sahip olduğunu göstermektedir ${ }^{11}$.

\section{Koloni Çağı Tabakaları}

\section{Konutlar}

Akropolisde 2006 yılından bu güne kadar yürütülen kazı çalışmalarında birçok yapı kalıntısı ortaya çıkarılmıştır (Bk. Fig. 3). Ancak kentin kuruluş dönemi ile bağlantılı mimari yapı kalıntılarına ise ancak 2015 yılı çalışmalarında rastlanabilmiştir. Kentin Arkaik Dönemi ile ilgili mimari ilk bulgu, akropol 1. terasın güneydoğu ucunda bulunan ve olasılıkla geçmiş dönemlerdeki bir deprem ya da toprak kayması sırasında çökmüş olan Orta Çağ surlarının yıkıntılarının kaldırılması

10 Yıldırım, "Söylenecek Çok Önemli”, s. 216.

11 Yıldırım, "Söylenecek Çok Önemli”, s. 216-217; Sümer Atasoy-Şahin Yıldırım, (ed.), Tios-Filyos Arkeolojik Kazı Projesi. Zonguldak'ta Bir Antik Kent TIOS, Ankara, 2015. s. 10. 
sırasında ortaya çıkarılmıştır. Bir diğer bulgu ise 2018 yllında yine aynı terasın doğu ucunda, Hellenistik Dönem surlarının hemen bitişiğinde yürütülen kazı çalışmaları sırasında bulunmuştur.

Doğu terasındaki bu çalışmaların neticesinde MÖ 7. ve 6. yüzyıllara tarihlenen, toplam dört adet konut kalıntısı ortaya çıarılmıştır. Bulunan konut yapılarının iki tanesi yuvarlak planlı, diğer ikisi de dikdörtgen planlıdır. Bu yapılar oldukça basit bir mimari düzenleme ile meydana getirilmişlerdir. Konutlar, zeminin hemen 1 ila $1,5 \mathrm{~m}$ altına açlan dikdörtgen ya da yuvarlak çukurların iç yüzeylerinin işlenmemiş yöresel taşlar ile örülmesi ile inşa edilmişlerdir. Bu çukurların üst örtüleri de olasılıkla tıpkı Kuzey Karadeniz örnekleri gibi saz ya da dallardan oluşturulmuş bir örtü ile kapatılmıştır. Oval olan konutların çapları 3m. civarındadır. Yapıların zeminleri sıkıştırılmış topraktan oluşmaktadır. Tespit edilen bütün konutlar birbirlerine oldukça yakın bir şekilde konumlandırılmışlardır. Araziye gelişigüzel yerleştirilen bu konutların aralarında cadde ve sokak oluşumuna dair bir emare bulunmamaktadır. Konutların hemen hepsinin zeminlerinde iki ayrı yangın tabakası ile karşılaşılmıştır. Buradaki ilk yangın tabakası MÖ 7. yüzyılın sonlarına tarihlenmektedir ve burada bulunan yanmış haldeki Orientalizan Dönem Güney Ionia seramikleri bu yangın tabakasını tarihlememizi sağlamaktadır. İkinci yangın diğerine oranla daha geniş bir alanı kaplamaktadır. Bu ikinci yangın tabakası ise burada bulunan çok sayıdaki Ionia kylixlerine ait parçalar ve az sayıdaki Attika seramiklerinden ötürü MÖ 6. yüzyılın ikinci yarısına tarihlendirilmiştir. Bu yangının Pers İstilası ile ilişkili olup olmadığı henüz belirlenememiştir. Bu son yangınla birlikte buradaki yapıların tahrip olduğu ve bir daha kullanılamadığı anlaşılmaktadır. Bu yangın tabakalarından elde edilen karbon parçaları üzerinde C14 testi uygulanması için gerekli girişimler başlatılmıştır.

\section{Yuvarlak Planlı Yapılar}

\section{P1 Yapisi}

Akropolisin Kuzeydoğu köşesinde bulunan ve olasllkla kentin Ceneviz hakimiyetinde kaldığı sırada inşa edilen bir burcun yıkıntılarının hemen altında çok miktarda Orientalizan ve Arkaik Dönemlere tarihlendirilen seramikler bulunmuştur. Söz konusu kale burcunun temelsiz olması, buradaki kalıntıların görece iyi korunmasını sağlamıştır. Sur duvarına ait molozların temizlenmesinin ardından burada yuvarlak planlı, 3m. çapında bir yapı kalıntısı ortaya çıkarılmıştır. $\mathrm{Bu}$ yapı akropoldeki diğer örnekler gibi yüzey zemininin altına açılmış bir çukur 
içine inşa edilmiş olup, bu çukurun iç yüzü işlenmemiş orta boy yassı taşlar kullanılarak tek sıra halinde örülmüştür. Yapının iç kullanım alanı yaklaşık $7 \mathrm{~m}^{2}$ dir. P1 olarak adlandırılan bu yapının korunan duvar yüksekliği $40 \mathrm{~cm}$. kadardır. (Bk. Fig. 3).

\section{P2. Yapisi}

Yuvarlak planlı bir diğer yapı kalıntısı ise 2018 yılı kazı sezonunda akropolün doğusunda bulunan ve Hellenistik Dönem'e tarihlendirilen sur duvarı ile bu sur duvarı ile bağlantılı Hellenistik mekan duvarlarının arasında bulunmuştur (Fig. $4,5)$. Bu alanda yapılan bir sondaj çalışması, Pl'deki konuta oranla çok daha iyi korunmuş bir konut yapısının ortaya çıkarılmasını sağlamıştır ancak, Hellenistik Dönem sur duvarlarının yapımı sırasında bu konutun iç yüz duvarının doğu bölümü tahrip edilmiştir. Bu oval planlı yapı da diğeri gibi $3 \mathrm{~m}$. çapındadır ve yaklaşık $7 \mathrm{~m}^{2}$ dir. Kullanılan inşa tekniği aynıdır. Yüzey zemininin altına açılmış basit bir çukurun iç yüzeyi, kaba işlenmiş taşlar kullanılarak tek sıra örülmüş, aralarında da bağlayıcı olarak çamur harç kullanılmıştır. Bu yapının korunan iç duvar yüksekliği yaklaşı 1 m.dir. Konut zemininin hemen ortasında bulunan yassı bir taş plaka, çatı örtüsünü taşıyan ahşap bir direkle bağlantılı olmalıdır.

\section{Dikdörtgen Planlı Yapılar}

\section{P3 Yapisi}

Akropolisde Koloni Çağı'na tarihlendirilen yuvarlak planlı konutlarla birlikte dikdörtgen planlı yapı kalıntıları da ortaya çıkarılmıştır. Ancak bu yapı kalıntıları yuvarlak planlı olanların aksine oldukça kötü durumdadırlar. Ortaya çıkarılan dikdörtgen planlı iki yapıdan sadece birisinin dörtte birlik bir köşesi günümüze kadar gelebilmiştir. P3 adı verilen bu yapı, Hellenistik Dönem sur duvarının hemen yanında yer almakta olup, sur duvarı inşa edilirken önemli ölçüde tahrip edilmiştir. Yapının korunan ölçüleri 3x1,5m.dir. Olasılıkla bu yapı da zemine açılan basit bir çukur içerisine inşa edilmiş ve bu çukurun iç yüzleri de tek sıra, kaba yontulmuş taşlar kullanılarak örülmüş̧ür (Bk. Fig. 3).

\section{P4 Yapisi}

P4 adı verilen bir diğger dikdörtgen yapı kalıntısından günümüze $3 \mathrm{~m}$. uzunluğundaki uzun yan duvar ile bu yan duvarın kuzeydoğuya bakan her iki ucunun $1 \mathrm{~m}$. kadar uzunluğa sahip çıkıntıları gelebilmiştir. Tek sıra olarak inşa edilmiş bu duvar kalıntılarının ortalama cidarı ise $40 \mathrm{~cm}$.dir. 
Koloni Çağı yerleşiminin bu kadar ağır bir şekilde tahrip olmasının ana nedeni akropolde görülen yerleşim yoğunluğudur. Şöyle ki akropol doğu terasta, Arkaik Dönem konutlarının da bulunduğu kültür tabakalarının kalınlığı çok fazla değildir. Bütün kültür tabakalarının toplam kalınlığı ana kayadan günümüz zeminine kadar 3m.civarındadır. Bu 3m.lik kültür tabakasında Arkaik, Klasik, Hellenistik, Roma, Bizans, Ceneviz ve Selçuklular'a ait çok sayıda yapı ve katman bulunmaktadır. Arkaik Dönem yapılarının bulunduğu tabaka, Hellenistik Dönem'de yapılan surlar ve diğer inşai faaliyetler neticesinde önemli ölçüde zarar görmüştür. Ancak, akropoldeki büyük tahribat, doğu terasın merkezinde gerçekleşmiştir. Bu terasta bulunan oldukça büyük ölçülere sahip Roma İmparatorluk Dönemi sarnıcı, Orta Bizans Dönemi Kilisesi ve bu kilise ile bağlantılı yapılar, ana kaya seviyesine kadar uzanan temelleri ile Arkaik, Klasik ve Hellenistik Dönem kalıntılarını neredeyse tamamen yok etmişlerdir.

Akropol ikinci teras ise Roma Dönemi mimarisinin en yoğun uygulandığı bölümdür. Bu terasta bulunan yapıların temelleri de ana kaya seviyesine kadar inmiştir. Bu yüzden burada da erken dönem tabakalarına ait mimari izler kaybolmuştur. Roma tapınağının inşası sırasında bütün teras yeniden planlanarak imar edilmiştir. Akropol 2. terasda erken dönemlere tarihlendirilen buluntuların sayısı oldukça azdır. Ancak, yine de buradaki kazılarda MÖ 7-6 ile 4. yüzyıllara ait olması muhtemel Dor başlıkları ve Dor başlıklarına ait parçalar bulunabilmiştir. Bu da burada Roma tapınağı öncesinde de tapınak binaları olduğunu göstermektedir. Özellikle bulunan Dor başlıkları, Arkaik ve de Hellenistik Dönem tapınaklarına ait en önemli bulgulardır.

Akropolisin 3. ve 4. teraslarında Geç Antik Dönem'e tarihlendirilen yapıların yoğunluğu diğer teraslara oranla daha azdır. Önümüzdeki ylllarda kentin erken dönemlerine ait kalıntılara ulaşabilmek için 3. ve 4. teraslarda yürütülecek çalışmalara daha fazla ağırlık verilecektir.

Karadeniz'in kuzeyinde yürütülen arkeolojik araştırmalar, Grekli ilk kolonistlerin Taman Yarımadası hariç çatılı ya da düz damlı çukur ya da yarı çukur evlerde yaşadıklarını göstermiştir ${ }^{12}$. Bu evlerin plan tipleri dikdörtgen, yuvarlak veya

12 R. GochaTsetskhladze, "On the Earliest Greek Colonial Architecture in the Pontus", (ed.) C. J. Tuplin, Pontus and the Outside World. Studies in Black Sea History, Historiography and Archaeology, (Colloquia Pontica 9), Leiden/Boston (2004), s. 225-278; R. Gocha Tsetskhladze, Karadeniz'in Tarih ve Arkeolojisi Üzerine: Arkaik ve Klasik Dönemlerde Karadeniz'de Ticaret: Bazı Gözlemler; İskit ile Thrak Kral ve Seçkin Mezarlarm Kim İnşa Etti?; Anayurtlar Dışındaki İoniahlar, İstanbul, 2005a, s. 97. 
ovaldir. Kuzey Karadeniz'de ortaya çıkarılan Arkaik yerleşmeler arasında Olbia ve Berezan dikkati çekmektedir. Olbia'da ortaya çıkarılan bir caddenin çevresinde 40 kadar çukur ev ortaya çıkarılmıştır. Berezan'da ise bu sayı 200'den fazladır' ${ }^{13}$. Berezan'daki çukur evlerin tarihi, MÖ 7. yüzyllın sonundan, MÖ 6. yüzyllın son çeyreğine kadar uzanmaktadır. Buradaki evler belirgin bir plan göstermez ${ }^{14}$. Olbia ve Berezan dışında Panticapaeum ${ }^{15}$ Chersonesus ${ }^{16}$ gibi önemli yerleşimler ile Gorgippia, Myrmekion, Tyramba, Nymphaeum, Nikonion, Kerkinitis gibi merkezlerde Arkaik Dönem'e tarihlendirilen çukur evler ile karşılaşılmıştır ${ }^{17}$. Güney Karadeniz'deki yuvarlak planlı konutlara Tieion haricinde Sinope'deki Kale Kazıları sırasında da rastlanılmıştır ${ }^{18}$. O. Doonen tarafindan burada yürütülen çalışmaların raporları yayınlanmışır.

Bu yapıların kökeni ve kullanım amacı ile ilgili çeşitli tartısmalar bulunmaktadır. G. R. Tsetskhladze, Kuzey Karadeniz'de ortaya çıarılan konutların bölgede yaşayan yerel topluluklarla ilintili olduğunu savunmaktadır. Yerel halkın yaşadığı yerleşim bölgelerinde bu tip çok sayıda konutun bulunduğunu, depolama ya da çöp için kullanılmış, buradaki konutlara oranla daha küçük boyutlara sahip pek çok çukur açıldığını belirtmektedir ${ }^{19}$. Kuzey Karadeniz'de Porthmion'da yapılan kazılarda ortaya çıkarılan taş temelli konutlar, sadece çukur evlerin konut olarak kullanılmadığını bize göstermektedir ${ }^{20}$. Kolonistlerin çok önemli bir bölümünün

13 Tsetskhladze, "Earliest Greek Colonial", s. 232; Tsetskhladze, Karadeniz'in Tarih, s. 97.

14 Tsetskhladze, "Earliest Greek Colonial", s. 232; Tsetskhladze, Karadeniz'in Tarih, s. 97; L. SergeiSolovyov, Ancient Berezan: The Architecture, History and Culture of the First Greek Colony in the Northern Black Sea, (ed.) J. Boardman ve G.R. Tsetskhladze, (Colloquia Pontica 4), Leiden/Boston/Cologne, 1999.

15 Vladimir P. Tolstikov, "Pantikapej - Stolitsa Bospora", (ed.) G. A Koshelenko, Ocherki Arkheologii Bospora, (1992), s. 45-99; Mikhail Y. Treister, "Excavations at Pantikapaion, Capital of theKingdom of Bosporus. Old Finds, Recent Results and some New Observations", (ed.) A. J. Todd, D. Komini-Dialeti ve D. Hatzivassihou, Greek Archaeologywithout Frontiers, Athens (2002), s. 152.

16 Miron I. Zolotarev, “Ранние этапы градостроительствав Херсонесе Таврическом” (Early stages of city building in Taurian Chersonessos), Chersonesskijsbornik 9, (1998), s. 26-35.

17 Tsetskhladze, "Earliest Greek Colonial". s. 225-278.

18 Owen Doonan-Hüseyin Vural-Andrew Goldman-Alexander Bauer-Jane Rempel-Suzan Sherratt-Ulrike Krotschek - Paolo Maranzana-Emine Sökmen, "Sinop Kalesi Archaeological Excavations, 2015-2016 Field Seasons", (ed.) S. Steadman ve G. Mc Mahon, The Archaeology of Anatolia: Recent Discoveries, vol. 2, Newcastle-upon-Tyne (2017), s. 179, 181, 193.

19 Tsetskhladze, Karadeniz'in Tarih, s. 99.

20 J. Marina Vachtina, "Archaic Buildings of Porthmion", (ed.) P.G. Bilde, J. M. Højte ve V. F. Stolba, The Cauldron of Ariantas: Studies presented to A.N. Ščeglov on the Occasion of his $70^{\text {th }}$ Birthday (Black Sea Studies 1), Aarhus (2003), s. 37-54. 
geldiği Ionia'da ise çukur ev olarak nitelendirilen bir konut yapısı henüz bulunamadı. Fakat bu mimarinin Anadolu'ya yabancı olmadığı anlaşılmakta ${ }^{21}$, buna benzer mimari pek çok dönem ve pek çok kültürde oldukça yaygındır sayıları çok fazla olmayan ve anavatanlarındaki konut mimarisi basit olan ilk kolonistlerin yeni bir çevrede taştan yapılmış, görkemli özel ya da kamu yapıları inşa etmeleri beklenemez. Bölgenin şartlarına uyum sağlamak yerel halk ile aynı mimariye sahip olmak daha mantıklı ve pratik olurdu. Karadeniz'e özgü çukur ve yarı çukur evlerin kıyılardaki bu bölgelerin ilk konut mimari örnekleri olmaları kuvvetle muhtemeldir. Bu çukur evler MÖ 6. yüzyıl sonunda taştan yapılmış konutlar onların yerini alana kadar varlıklarını sürdürmüşlerdir ${ }^{22}$. Ancak Tieion'da henüz bu tip konutlara rastlanılamamıştır.

\section{Demir Atölyesi(?)}

Akropol Doğu terasta 2019 yllında gerçekleştirilen kazı çalışmalarında P2 konutunun hemen $1 \mathrm{~m}$. kadar yanında bir demir atölyesine ait olması muhtemel bir oluşum ortaya çıarılmıştır. Demir işliği ana kayanın hemen üzerine yapılmıştır. Işliğin oval planlı bir ocak bölümü bulunmaktadır (Fig. 6). Bu oval ocak kalıntısının içerisinden yoğun miktarda kül ve çok sayıda demir cürufu kalıntısı ortaya çıkarılmıştır (Fig. 7). Ocak ve kanal bölümü tıpkı yanındaki çukur evler gibi, toprak içerisine açllan bir çukurun içinde oluşturulmuştur. Kanal bölümünün ise üzeri örtülmüştür. Bu yapının ocak bölümünün bir kısmı, Hellenistik Dönem’e tarihlendirilen duvar kalıntısının altında kalmıştır. Bundan dolayı ocağın tamamını ölçmek mümkün olmamıştır. İşliğin ocak bölümünün çapı yaklaşık $1 \mathrm{~m}$. kadardır. Düzensiz köşeli taşlar kullanılarak meydana getirilmiştir. Ocağın doğusu, batıya oranla daha iyi korunmuş durumdadır. İşliğin korunan yüksekliği $67 \mathrm{~cm}$.dir. Ocağın doğu bölümünde 2,5m. uzunluğunda, $30 \mathrm{~cm}$. genişliğinde şist taşları kullanılarak meydana getirilmiş bir kanal bulunmaktadır. Kanalın üzeri yine şist taşı plakalar kullanılarak kapatılmıştır.

İşliğin planını tam olarak belirleyebilmek için hemen üzerinde bulunan Hellenstik Dönem duvarlarının küçük bir bölümü gelecek kazı sezonunda traşlanacaktır.

21 R. GochaTsetskhladze, "Note on semi-pithouses and handmade pottery from Gordion", (ed.) A. Avram ve M. Babes, Civilisation grecque et cultures antiques périphériques: Hommage à Petre Alexandrescu à son 70 e anniversaire, Bucharest (2000), s. 165-170.

22 Tsetskhladze "Note on semi-pithouses"; 2004, s. 253-262; Tsetskhladze, Karadeniz'in Tarih, s. 99. 
Kuzey Karadeniz'de Berezan'da ${ }^{23}$ ve Batı Karadeniz'de Apollonia Pontika'da ${ }^{24}$ Arkaik Dönem'e tarihlendirilen metalürjik bulgular ortaya çıarılmıştı. Ancak buralarda bulunan bakır cüruflarının aksine Tieion'da demir cürufları ortaya çımmaktadır. Tieion ve çevresindeki metalürjik araştırmalar henüz çok yenidir. Yakınlardaki maden yataklarının ya da cevherlerinin varlığı ile ilgili henüz doyurucu bir bilgi elde edilememiştir. Önümüzdeki yllarda bu konu üzerine çalışmaların yoğunlaştırılması planlanmaktadır.

\section{Buluntular}

\section{Doğu Yunan Seramiği}

Akropol Doğu terasta 2015 ve 2019 yılları arasında yürütülen çalışmalarda iki yüz civarında Oriantalizan Dönem'e tarihlendirilen Doğu Yunan seramiği parçası bulunmuştur. Bu seramikler baskın olarak Güney Ionia atölyeleri tarafindan üretilmişlerdir. Bununla birlikte Kuzey Ionia atölyelerinin ürettikleri seramiklere az da olsa rastlanılmaktadı2 ${ }^{25}$. Güney Ionia atölyeleri arasında ise Miletos üretimi olan kaplar ağırlıktadır. Miletos ile birlikte Khios, Klazomenea, Kuzey İonia (Teos?) üretimi kaplarla birlikte yerel üretim kap örnekleri de çok sayıda karşımıza çımıştır. Ionia üretimi kaplar ile birlikte Arkaik Dönem Korinth üretimi scythos ve aribalollos parçalarına da az sayıda da olsa rastlanılmaktadır. Bununla birlikte Arkaik Dönem Attika üretimi siyah firnisli kap örnekleri ise, diğger atölyelere oranla daha az miktarda bulunmuşlardır.

Doğu Yunan seramiğinde önemli bir yere sahip olan Yaban Keçisi Stili R. M. Gook tarafindan, Erken Yaban Keçisi, Orta Yaban Keçisi ve Geç Yaban Keçisi olarak üçe ayrılmıştır. Bu kapların çok önemli bir bölümü Ionia ve Ionia'ya yakın atölyelerde imal edilmişlerdir ${ }^{26}$. Güney Ionia ise, Orta Yaban Keçisi stilinde başı

23 Tsetskhladze, Karadeniz'in Tarih, s. 98.

24 Margarit Damyanov, "On the Chronology of the Earliest Greek Metallurgy in Apollonia Pontica (Poster presented)", The 19th International Congress of Classical Archaeology-Archaeology and Economy in the Ancient World, (22-26 May 2018), Cologne/Bonn, 2018.

25 Atasoy-Erpehlivan, "Tios'da Erken Yerleşmeye", s. 202.

26 R. Manuel Cook, "Fikellura Pottery", Annual of the British School at Athens 34, (1933-34), s. 2; R. Manuel Cook, "Ionia and Greece in the 8th and 7th Centuries B.C.", JHS 66, (1946), s. 9395; R. Manuel Cook, "The Wild Goat and Fikellura Styles: Some speculations", Oxford fournal of Archaeology 11.3, (1992), s. 255; Michael Kerschner-Udo Schlotzhauer, "A new Classification System for East Greek Potter", Ancient West and East 4.1, (2005), s. 1-56. 
çekmektedir ${ }^{27}$. Tieion akropolisinde ortaya çıkartılan buluntuların en eskileri MÖ 7. yüzyılın son çeyreğine tarihlendirilen Orta Yaban Keçisi 2 stilindeki Güney Ionia üretimi seramik parçalarıdır (Fig. 8). Özellikle akropolde 2018 ve 2019 yıllarında yuvarlak planlı konutlarda yürütülen kazılarda, konutların hemen hemen anakaya seviyesinde olan ve sıkıştırılmış topraktan meydana getirilen taban seviyelerinde, bu kap parçaları ile sıkça karşılaşılmıştır. Yukarıda da belirttiğimiz üzere bu konutlar iki ayrı yangın tabakasından etkilenmiştir. MÖ 7. yüzyıl tabakasında karşılaştığımız ilk yangın tabakası, P2 yapısının en altta bulunan taban kotunda karşımıza çıkmıştır. Orta Yaban Keçisi 2 stilindeki seramiklerin hepsi bu yangın tabakasının içinde bulunmuşlardır.

Doğu Yunan seramikleri arasında yine Güney Ionia bilhassa Samos ve Miletos ile ilişkilendirilen kylixler oldukça önemli yer tutar. Acropoliste bulunan Doğu Yunan seramikleri arasında şimdiye kadar en çok çıkan kap türü Ionia kylixleridir (Fig.9). MÖ 7. yüzyılın sonlarından, MÖ 6. yüzyılın ortalarına kadar tarihlendirilmektedirler ${ }^{28}$. Tieion'da birkaç tip ile temsil edilen bu kylixler, arasında gözlü kylixlere de rastlanılmaktadır (Fig. 10). Amphoralar arasında ise özellikle Khios üretimi beyaz astarlı amphoralar sayıca fazladırlar. MÖ 7. yüzyılın sonlarına tarihlendirilen ${ }^{29}$ bu depolama kaplarından çok sayıda örnek elimizde mevcuttur. Tieion'da günümüze kadar sadece bir örneği bulunan kuşlu kaselerin üretim yerleri ise tartısmalıdır (Fig. 11). Ancak son zamanlarda bu kapların ana üretim yerinin tespiti amacıyla yapılan analizlerin sonuçlarına göre Kuzey Ionia'da birkaç merkez belirgin bir şekilde öne çıkmaktadır ${ }^{30}$.

Akropolis Doğu terasta bulunan Doğu Yunan seramikleri ile ilgili kapsamlı bir

28 Atasoy-Erpehlivan "Tios'da Erken Yerleşmeye”, s. 202-203; Udo Schlotzhauer, "Ausgewählte Beispiele ostgriechischer Keramik aus Naukratis im Blickwinkel neuer Forschungen”, (ed.) U. Höckmann, ve D. Kreikenbom, Naukratis: Die Beziehungen zu Ostgriechenland, Ägypten und Zupern in archaischer Zeit (Akten der Table Ronde Mainz, November 1999), Möhnesee (2001), s. 123-124; Cook-Dupont, East Greek Pottery, s. 129.

29 Yusuf Sezgin, Arkaik Dönem İonia Üretimi Ticari Amphoralar, İstanbul, 2012, s. 83-136.

30 Pierre Dupont,"Naturwissenschaftliche Bestimmung der Archaischen Keramik Milets", (ed.) W. Müller-Wiener, Istanbuler Mitteilungen Beiheft 31, Tübingen (1986), s. 61-63; Richard E Jones, Greek and Cypriot Pottery, A Review of Scientific Studies, British School at Athens, Fitch Laboratory Occasional Paper 1, Athens, 1986, s. 661; Michael Kerschner-H. Mommsen-Meral Akurgal-W. Dietrich Niemeier, Töpferzentren der Ostagais: Archaometrische und archaologische Untersuchungen zur Mykenischen, geometrischenund archaischen Keramik aus Fundorten in Westkleinasien, Ergänzungshefte zu den Jahresheften des Österreichischen Archaologischen Institutes in Wien 3, Vienna, 2002, s. 63-72, 149. 
yayın projesi başlatılmış olup bu projenin sonuçları M. Vakhtina, Ş. Yıldırım tarafindan birlikte yayınlanacaktır ${ }^{31}$.

\section{Gri Mal Seramik}

Hem yuvarlak planlı hem de dikdörtgen planlı konutlarda Doğu Yunan Seramiği ile birlikte yine bu yapıların içinde ve çevresinde yürütülen çalışmalarda, çok sayıda yerel üretim, üzerlerinde bazen firça ile yapılmış zig zag, üçgen ve damataşı motifleri, bazen de ip baskısı, kazıma ya da parmak baskısı ile yapılmış motifler olan genellikle koyu gri, siyah ve koyu kahverengi hamurlu, elde ve çarkta yapılmış seramik parçaları da ortaya çıkarılmıştır. Kapların önemli bir bölümünün üzerinde herhangi bir bezeme yer almamaktadır. Bazı kaplarda ise gövde üzerindeki kabartma şerit bant üzerine parmak baskısı yapıldığı görülmektedir. Bu seramiklere Akropolün Arkaik Dönem’e tarihlendirilen bütün tabakalarında yoğun bir şekilde rastlanılmaktadır. Tieion’da ortaya çıkarılan Gri Mal kapların bilhassa firça ile yapılmış geometrik desenli olanları, Kuzey Karadeniz'deki kazılarda ortaya çıkarılan ve Barbar Seramiği olarak adlandırılan buluntuların aksine oldukça kalitelidir (Fig. 12). Gri Mal seramiğinde mutfak kapları, içki kapları ve depolama kapları yoğunluktadır. Kapların önemli bir bölümünde perdah izi görülür. Kaba mutfak kaplarında mika oranı diğer kaplara oranla daha yüksektir. Akropoldeki kazılar sırasinda Gri Mal seramikle birlikte Siyah Mal olarak da adlandırabileceğimiz yerel bir seramik türüne daha rastlanılmaktadır. Ancak bu seramik gri olanlarına oranla daha az sayıdadır. Siyah Mal seramikler Erken Demir Çă̆ı başlarında Balkanlar'da, Thrace'de ve Troia'da VIIb2 tabakasında görülen ve Buckelkeramik olarak da adlandırılan kaplara hamur, form, yapım tekniği ve bezeme olarak oldukça benzemektedir.

2019 yılı kazı sezonunda akropolisin batı ucunda bulunan ve Bizans Dönemi’ne tarihlendirilen bir sarnıç yapısının kazısı gerçekleştirilmiştir. Sarnıca akropolisden ulaşımı sağlayan tonozlu dehlizin çökmesiyle birlikte dehlizin içerisine akropolden gelen toprak tabakaları dolmuştur. Bu dolgunun içinde ise çok sayıda Orientalizan Dönem Doğu Yunan seramiği ile birlikte Gri Mal seramikler de bulunmuştur. $\mathrm{Bu}$ dolguda bulunan seramikler arasında ise bir tanesi oldukça ilgi çekicidir. Bu seramik koyu gri renkli bir kaba ait gövde parçasıdır. Bu parçanın üzerinde dört karakterden oluşan "EIES" ya da "EGES" yazdığı düşünülen Phrygce bir yazıt

31 Akropolde ortaya çıkarılan Doğu Yunan seramikleri Dr. Marina Vakhtina ve Dr. Şahin Yıldırım tarafindan yayına hazırlanmaktadır. 
bulunmaktadır. A. Avram tarafindan "Eski Phryg Yazısı/Dili - Old Phrygian Language" olarak değerlendirilen bu yazıtın olasılıkla MÖ 7-6. yüzyıllar arasına tarihlendiği düşünülmektedir. Bununla birlikte akropolde bulunan ve üzerinde ne yazdığı henüz deşifre edilmemiş bir seramik kap parçası üzerinde de kazıma tekniğiyle oluşturulmuş bir yazıta daha rastlanılmıştır. Bu yazıtlar Doç. Dr. Bülent Öztürk ve A. Avram tarafindan yayına hazırlanmaktadır (Fig. 13).Phrygia'nın başkenti Gordion'da yürütülen kazı çalışmaları sırasında da üzerinde Phryg alfabesi ile yazılmış yazıların bulunduğu birçok seramik parçası bulunmuştur. $\mathrm{Bu}$ seramiklerin önemli bir bölümü MÖ 8. ve 7 . yüzyllara tarihlendirilmektedir ${ }^{32}$.

Akropolde bulunan Gri Mal seramik buluntularının hemen hepsi MÖ 7-6. yüzyllara tarihlendirilen tabakalardan gelmektedir. Bu seramikler Grek Koloni Çağı seramikleri ile aynı kontekste bulunmuşlardır. Bu da bizim Tios'da bulunan kolonistlerle yerel Proto Phryg toplulukların bire bir iletişim halinde olduklarını ve birbirleri ile iyi ilişkiler kurduklarını düşündürtmektedir. Ancak kesin bir yargıya varmak için henüz çok erkendir. Akropolde bulunan Orrientalizan ve Arkaik Dönem'lere tarihlendirilen Grek seramiğinin beş katından daha fazla miktarda Gri Mal olarak adlandırdığımız yerel Phryg menşeili seramik bulunmuştur.

Gri Mal, diğer bölgelerin aksine İç ve Batı Anadolu'da oldukça yoğun bir şekilde karşımıza çıkmaktadır ${ }^{33}$. Bu durum Phryglerin bu bölgedeki varlı̆̆ılla doğrudan bağlantılıdır. Bu seramik kap formları neredeyse hiç değişmeden Orta ve Geç Demir Çağı boyunca geniş bir coğrafyada yer almakta ve bu seramiklerin kullanımı bazı bölgelerde Hellenistik ve Roma dönemlerine kadar uzanmaktadır ${ }^{34}$. Bu

32 Rodney Young, Old Phrygian Inscriptions from Gordion: Toward a History of the Phrygian Alphabet, (Hesperia Suppl. 38), Athens, 1969, s. 252-296; Claude Brixhe-Lejeune Michel, Corpus des Inscriptions Paleo-Phrygiennes, Paris, 1984.

33 Lisa Kealhofer-Peter Grave-Ben Marsh-Sharon Steadman-L. Ronald Gorny-D. Geoffrey Summers, "Patterns of Iron Age Interaction: Three sites in Yozgat Province", Anatolian Studies 60, (2010), s. 71-92.

34 Robert Henrickson, "Continuity and Discontinuity in the Ceramic Tradition of Gordion during the Iron Age". (ed.) D. French, ve A. Çilingiroğlu, Anatolian Iron Ages 3 (Proceedings of the Third Anatolian Iron Ages Colloquium held at Van, 6-12 August 1990) (British Institute of Archaeology at Ankara, Monograph 16), London (1994), s. 95-129; Robert Henrickson-PamelaVandiver-James Blackman, "Lustrous Black Fine Ware at Gordion, Turkey: A Distinctive Sintered Slip Technology", (ed.) P. B. Vandiver, M. Goodway, ve J. L. Mass, Materials Issues in Art and Archaeology VI (Symposium held November 26-30, 2001, Boston, Massachusetts, Materials Research Society Symposia Proceedings 712), Warrendale, PA (2002), s. 391-400; Robert Henrickson, "The Local Potter's Craft at Phrygian Gordion", (ed.) L. Kealhofer, The Archaeology of Midas and the Phrygians: Recent Work at Gordion, Philadelphia (2005), s. 124-135; G. Kenneth Sams, The Early 
seramiğe Güney Karadeniz’in iç bölgelerinde de rastlanılmaktadır. Bithynia'nın Doğu komşusu olan Paphlagonia'da R. Matthews tarafindan gerçekleştirilen araştırmaların sonuçlarına göre, bu seramik, bütün güneybatı Paphlagonia buluntuları arasında en belirgin Demir Çağı grubu olarak nitelendirilmektedir ${ }^{35}$. Matthews tarafindan bu durum Phryg kültürünün Anadolu'nun kuzeyine yansıması olarak değerlendirilmiştir ${ }^{36}$. Sinop'ta Ekrem Akurgal tarafindan yürütülen kazılarda da MÖ 7. ve 6. yüzyıllara tarihlenen Doğu Yunan seramiği ile birlikte çok sayıda Phryg seramiği ortaya çıkarılmıştı. Bu durum iç bölgelerle geliştirilen iyi ilişkilere bir kanıt olarak yorumlanmışıı ${ }^{37}$.

Bununla birlikte Tieion'a kuş uçumu $80 \mathrm{~km}$. mesafede olan Hadrianoupolis ve Cimistine'de yürütülen araştırmalarda da bu seramiğe rastlanılmıştır ${ }^{38}$. Aynı zamanda Heracleia Pontica yakınlarında bulunan İnönü Mağarası kazılarında da bu türde seramik buluntuları ortaya çıkarılmıştır. Kazıyı yürüten H. Ekmen, bu buluntuları Troia VIIb1 ve VIIb2 kültürleri ile ilişkilendirmekte, Balkanlar'dan Anadolu'ya Geç Bronz Çağı sonu, Erken Demir Çağı başlarında meydana geldiği düşünülen göçlerle bağlantılı olduğu savını öne sürmektedir ${ }^{39}$. Phryglerin başkenti Gordion'da yürütülen kazılar sonucunda ortaya çıkarılan Erken Demir Çağı'na tarihlendirilen çukur konutlarda da az miktarda el yapımı seramikler bulunmuştu $^{40}$. Bu seramiklerin varlığı ile Phryglerin Thraklar gibi Balkanlar'dan gelme bir topluluk olduğu yönünde bir görüş de belirginleşmeye başlamıştır ${ }^{41}$.

Phrygian Pottery, Gordion Excavations 4.1-2; University Museum Monograph 79, Philadelphia, 1994; S. Marie Stewart, Gordion After the Knot: Hellenistic Pottery and Culture, (Ph.D. dissertation), University of Cincinnati, Cincinati, 2010, s. 49-50; G. Dechkova Toteva, Local Cultures of Late Achaemenid Anatolia, (Ph.D. dissertation), University of Minnesota, 2007, s. 53, 59.

35 Roger Matthews-Claudia Glatz, At empires' edge; Project Paphlagonia, regional survey in North central Turkey, British Institute of Archaeology at Ankara, London, 2009, s. 153.

36 Matthews-Glatz, Project Paphlagonia, regional, s. 153.

37 Akurgal - Budde, 1956, s. 9.

38 Ergün Laflı-K. Şahin Gülseren, "Iron Age and Hellenistic Ceramics from Southwestern Paphlagonia", Archaeology and Science 7, (2012), s. 9-166; Ergün Lafl-K. Şahin Gülseren-Sami Patac1, "Iron Age Ceramics from Southwestern Paphlagonia", ssAnatolia Antiqua 21, (2013), s. 3368.

39 Hamza Ekmen-Ahmet Mercan-Gülden Ekmen-Ali Güney, "İnönü Mağarası 2017 Yılı Kazıları", KST XXXX/II, Ankara (2019), s. 274.

40 R. Gocha Tsetskhladze, "Early Iron Age Societies of the Black Sea region and Anatolia: Some Observations", (ed.) G. Darbyshire ve A. Çilingiroğlu, Anatolian Iron Ages 5 (Proceedings of the Fifth Anatolian Iron Ages Colloquium held at Van, 6-10 August 2001) (British Institute of Archaeology at Ankara Monograph 31), London (2005b), s. 214.

41 M. Mary Voight, "Excavations in Gordion 1988-1989; the Yassihöyük Stratigraphic Se- 
Gri Mal seramiğge Güneybatı Karadeniz kıyısında arkeolojik konteks olarak ilk defa Tieion'da rastlanılmıştır. Eldeki Phrygce seramik yazıtları ve seramiklerin bazılarının üzerlerinde görülen dama taşı, zig zag ve üçgenler gibi Phryg motifleri, Tieion gri mal seramiğinin oldukça önemli bir bölümünün Phryg Kültürü ile bağlantılı olduğunu göstermektedir. Tieion siyah ve gri mal seramikler üzerine yürütülen ayrıntılı araştırmalar ise devam etmektedir.

Yukarıda da değindiğimiz gibi, Karadeniz kıyılarında, tıpkı Tieion'daki Siyah Mal olarak adlandırdığımız seramik tipine benzeyen, el yapımı bir seramik daha vardır. Kuzey Karadeniz'deki arkeolojik araştırmaları yürüten araştırmacıların bir bölümü tarafindan "Barbar Seramiği” olarak da adlandırılan bu seramiğe, Karadeniz'in hem kuzeyinde hem de batısında erken dönem yerleşimlerinde sıkça rastlanılmaktadır. Kuzey Karadeniz'de ortaya çıkarılan bu seramiklerin o bölgelerde yaşayan yerel toplumlarla bağlantılı olduğu düşünülmektedir² ${ }^{42} \mathrm{Bu}$ seramiğe Romanya'da Istros ${ }^{43}, \operatorname{Odessos}^{44}, \operatorname{Tomis}^{45}$, Apollonia Pontika $^{46}$, Berezan $^{47}$, $\mathrm{Olbia}^{48}$ gibi birçok kentte rastlanılmıştır. Karadeniz’in kuzeyindeki yerleşimlerde bu seramiğin menşei ile ilgili tartışmalar halen devam etmektedir.

quence",(ed.) D. H. French, ve A. Çilingiroğlu, Anatolian Iron Ages 3 (Proceedings of the Third Anatolian Iron Ages Colloquium held at Van, 6-12 August 1990) (British Institute of Archaeology at Ankara, Monograph 16), London (1994), s. 285.

42 R. Gocha Tsetskhladze, "The Greek Colonisation of the Black Sea Area: Stages, Models, and Native Population" (ed.) G. R. Tsetskhladze, The Greek Colonisation of The Black Sea Area: Historical Interpretation of Archaeology, (Historia Einzelschriften 121), Stuttgart (1998), s. 44-47; Tsetskhladze, "On the Earliest", s. 262-268. Various ancient sources state that many local communities lived around the Black Sea such as the Thracians, Getae, Cimmerians, Scythians, Mariandyni, Tibareni, Eneti, Chalybes, Macrones etc. (Tsetskhladze, "The Greek Colonisation”, s. 44-50.)

43 Suzaria Dimitriu, "Cartierul de locuinte din zona de vest a cetatii, inepoca arhaica Sapaturi 1955-1960”, (ed.) E. Conduraci, Histria 2, Bucharest (1960), s. 54-56.

44 Goranka Toncheva, "Arhaichiya materiali ot Odesos", Izvestiya na Arheologicheskiya Institut 30.1, (1967), s. 173.

45 Lucian Arsenie, "Ceramica lucratâ cu mâna la Tomis - stadiul actual al cercetârilor", Pontica 33-34, (2000-2001), s. 283-298.

46 Krastina Panayotova-Margarit Damyanov-Daniela Stoyanova-Teodora Bogdanova, "Apollonia Pontica: The Archaic Temenos and Settlement on the Island of St. Kirik" (Poster sunum), (ed.) J. M. Alvarez, T. Nogales ve I. Rod, Centre and Periphery in the Ancient World, (Proceedings of the XVIIIth International Congress of Classical Archaeology I Merida 13.-17. May 2013), 2014.

47 Konstantin Konstantinovich Marchenko, Varvary v sostave naseleniya Berezani i Ol'vii, vo vtoroi polovine VI - pervoi polovine IV. do n.e.: po materialam lepnoi Keramiki, Leningrad, 1988, s. 131; L. Sergei Solovyov, Ancient Berezan: The Architecture, History and Culture of the First Greek Colony in the Northern Black Sea, (ed.) J. Boardman ve G. R. Tsetskhladze, (Colloquia Pontica 4), Leiden/ Boston/Cologne, 1999, s. 43-58.

48 Marchenko, naseleniya Berezani, s. 131; Solovyov, Ancient Berezan, s. 43-58. 


\section{Pişmiş Toprak Figürinler}

Akropol Doğu terasta P1 konutunun içinde iki adet terracotta at başı figürini bulunmuştur (Fig. 14 sol). En altta bulunan arkeolojik tabakada bulunan bu figürinler oldukça ilgi çekicidir. Birinci figürin olasılıkla yerel üretimdir. Terracotta at figürünün boynunun ve başının bir kısmı korunmuştur. Gözü boya ile işlenmiş, figürün kulaklarının olduğu üst bölümü ise kırılmıştır. Figürün burun ve ağız kısmı incelerek ileri uzanmaktadır ancak büyük bir kısmı kırık ve noksandır. Boyundan başa geçiş kısmında iyi korunan tek bölüm göz kısmıdır. Siyah boya ile badem formundaki gözün ortasında nokta şeklinde iris işlenmiştir. Boya ile belirtilmiş olan gözün badem formunda oluşu MÖ 7. yüzylldan itibaren vazo resimlerinde görülmektedir. Gözün hemen altında oluşturulmuş üçlü yatay insize kısa çizgi grubu ve bu yatay çizgi grubunun bir santimetre kadar altında yine insize/kazıma üçlü çizgi grubu ile oluşturulmuş "zigzag" motifi ise atın boyun kısmına işlenmiştir. İkinci figürin ise kalıp yapımıdır (Fig. 14 orta ve sağ). Atın boyundan başa geçiş kısmı ve başı korunmuştur. Başın arka kısmında yele dikdörtgen bir çıkıntı olarak verilmiş, başın üst kısmındaki yele bölümü ise kırılmıştır. Kulaklar el ile biçimlendirilmiştir. Atın să̆ kulağının önünde göz yüzeysel bir kazıma çizgi ile belirtilmiştir. Burun kısmı önde düz olarak bitirilmiştir. Burnun sol yanında $0,7 \mathrm{~cm}$ çapında daire biçimli ek yeri(çıkıntı) göze çarpar. Olasılıkla burada yer alan bir parça kırılmışıı. Belki de Geç Geometrik Dönem'e tarihlendirilen bazı bronz figürinlerde de görüldüğü üzere birkaç attan oluşan bir gruba aittir. Figürin siyah firnis(glaze) ile kaplanmıştır.

Orta Geometrik Dönem'den itibaren seramikler üzerinde görülmeye başlanan at figürleri4 ${ }^{49}$, Geç Geometrikte oldukça yaygınlaşan mezar kapları olan amphora, krater benzeri formlar üzerindeki cenaze sahnelerinin bir parçası olarak karşımıza çıkmaya başlar ${ }^{50}$. Özellikle Geç Geometrik'te MÖ 8.yüzyılın ortaları ve son çeyreği içerisinde, vazolar üzerinde görülen at figürlerinin siluet şeklinde betimlenmesi, yelenin belirtilmeye başlaması ve burnun da bir trompet formunda öne doğru düz uzanması yaygın form özelliği olarak görülür ${ }^{51}$. Vazolar üzerinde görülen at figürlerinde görülen ikonografik özelliklerin MÖ 8. yüzyllın ortalarından

49 J. Nicolas Coldstream, Geometric Greece: 900-700 BC, 2nd ed., London, 2003, s. 54-56, fig. $24 \mathrm{a}$.

50 Coldstream, Geometric Greece, s. 88-101, figs. 33a, 34a, 35d, 37a-d.

51 D. Gordon Mitten, "The Earliest Greek Sculptures in the Museum", Boston Museum Bulletin, 339, (1967), s. 4-18, fig. 3. 
itibaren bronz at figürinlerinde de yaygınlaştığı görülür ${ }^{52}$. MÖ 8. yüzyıldan itibaren Geometrik Dönem'e tarihlendirilen Atina mezarlarında bulunan pyxislerin kapaklarına da tutamak olarak at figürlerinin eklendiği görülür ${ }^{53}$. MÖ 8. yüzyılın son çeyreğinde ise oldukça yaygınlaşır. At figürlerinin yaygınlaşması, olasılıkla Homeros'un İlyada destanında konu edildiği vazolar üzerindeki cenaze sahneleri ve araba yarışları ile ortaya çıkan kahramanlık kültünün işareti olarak yorumlanmaktadir.

Tieion'daki at figürinleri ile ilgili bazı soru işaretleri bulunmaktadır. En önemli konu bunların tarihlendirilmesi konusudur. Özellikle siyah firnisli at figürinin Geç Geometrik Dönem örnekleriyle bazı önemli benzerliklerinin olması oldukça ilgi çekicidir. Ancak akropoldeki bütün arkeolojik veriler, terminus ante quem olarak MÖ 7. yüzyılın son çeyreğini işaret etmektedir. Bu buluntu grubunun net olarak tarihlendirilmesi üzerine çalışmalar devam ettirilmektedir ${ }^{54}$.

\section{Değerlendirme ve Sonuç}

Tieion acropolisinin doğusunda bulunan 1. terasdan elde edilen veriler, Güney Karadeniz arkeolojisi açısından oldukça önemli sonuçlar vermektedir. Güney Karadeniz'deki Grek Kolonizasyonu ile ilgili ilk ciddi bulgulara Tieion'da rastlanılmış ve bulunan bu konut yapıları, Oikistlerin tıpkı Kuzey Karadeniz'deki bazı yerleşimler gibi çukur konutlar kullandıklarını göstermiştir. Tieion'da bulunan Doğu Yunan seramikleri, bilhassa da Orta Yaban Keçisi 2 evresine tarihlendirilen parçalar, Samsun Akalan ${ }^{55}$ ve Sinop'ta ${ }^{56}$ bulunanlar hariç, bir ilktir. Güney Batı Karadeniz kıyısında yaşayan yerel halklardan birisinin Phryg orjinli bir toplum olduğunu söyleyebilecek derecede yoğun seramik buluntusu ve önemli

52 Coldstream, Geometric Greece, s. 129, 156, figs. 48 a-b, 58b; Mitten, "The Earliest Greek", s. 4-18, fig. 3; Mary Voyatzis, "Votive riders seated side-saddle at early Greek sanctuaries", Annual of the British School at Athens 87, (1992), s. 259-279, fig. 1-5.

53 Rodney Young, Late Geometric Graves, s. 80; Barbara Bohen, Die Geometrischen Pyxiden, Kerameikos 13, Berlin, 1988, s. 8-12, 74-76; Barbara Bohen, "The Boeotian Origin of an Unusual Geometric Vase", The 7. Paul Getty Museum Fournal 20, (1992), s. 41-44.

54 Bu pişmiş toprak at figürinleri, Bartın Üniversitesi Öğretim Üyesi Dr. Fatma Bağdatlı Çam tarafindan ayrıntılı bir şekilde yayınlanacaktır.

55 W. Willson Cummer, "Iron Age Pottery from Akalan". Mitteilungen des Deutschen ArchäologischenInstituts, Abteilung Istanbul 26, (1976), s. 31-36, pl. 7.

56 Ekrem Akurgal, "Sinop Kazıları”, Türk Arkeoloji Dergisi 6.1, (1956), s. 48 Ekrem Akurgal-LudwigBudde, Vorläufiger Bericht über die Ausgrabungen in Sinope, TTKY 14, Ankara, 1956, s. 4-7; Yusuf Boysal, "Sinop'un En Eski Buluntuları ve Kolonizasyonu Hakkında", Türk Arkeoloji Dergisi 8.2, (1958), s. 23-29. 
arkeolojik veriler ele geçirilmiştir. Bununla birlikte Eski Phryg alfabesiyle yazılmış çömlek parçaları da bu bölgede tespit edilmiş ilk Phryg yazıtlarıdır. Phryglerin MÖ 7. yüzyılda bölgenin iç kısımlarındaki varlıkları ile ilgili çok sayıda bulgu söz konusudur. Tieion'a en yakın bulgu ise kuş uçumu 25km. ötede olan Gökçebey’de kurtarma kazıları sonrasında ortaya çıkarılan bronz Phryg fibulasıdır (Fig. 15). Gökçebey'de bulunan Çanakçılar Özel Müzesi envanterine geçtiğimiz yıllarda giren $25 \mathrm{~cm}$ çapında, 6cm. yüksekliğindeki bronzdan yapılmış omphaloslu bir kap da Gökçebey’e çok yakın bir tümülüste bulunmuştur (Fig. 16). İkonographik özellikleri açısından MÖ 8-7. yüzyıllara tarihlendirilmektedir ${ }^{57}$. Bölgeye yaklaşık 100km. kadar uzaklıkta olan Safranbolu'da MÖ 9-8. yüzyıllara tarihlendirilen Büyük Göztepe tümülüsünde de Phryg seramiği parçaları ortaya çıkarılmıştır ${ }^{58}$. Ayrıca Safranbolu çevresindeki kaya mezarlarında da Phryg etkileri görülmektedir. Bunlardan özellikle Soğanlı Vadisi’ndeki Karakoyunlu köyünde bulunan ve MÖ 4. yüzyıla tarihlendirilen bir kaya mezarının üçgen alınlıklı fasadında bu etki belirgin bir şekilde hissedilir (Fig. 17) ${ }^{59}$. Tieion'a kuş uçuşu 60 km. uzaklıkta olan Heracleia Pontike yakınlarındaki Alaplı kırsalında bulunan ve Ereğli Müzesi'nde sergilenen MÖ 9-8. yüzyıllar arasına tarihlendirilen Kybele Kült heykeli de bölgedeki güçlü Phryg mirasının kalıntıları şeklindedirler (Fig. 18).

Tieion'un kurucularının baskın Phryg kültüründen etkilenmemeleri düşünülemez. Phryg kökenli bir tanrı olan Zeus Syrgastes'in ${ }^{60}$ Tieion antik kentinin en önemli

57 O. White Muscarella, "Phrygian or Lydian?”, fournal of Near Eastern Studies 30, (1971), s. 49, pl. IV, fig. 9.

58 Şahin Yıldırım, "A Great Tumulus from Paphlagonia", (ed.) G. R. Tsetskhladze ve S. Atasoy, Settlements and Necropoleis of the Black Sea and its Hinterland in Antiquity (Selected Papers from the Third International Conference 'The Black Sea in Antiquity and Tekkeköy: An Ancient Settlement on the Southern Black Sea Coast', 27-29 October 2017, Tekkeköy, Samsun), Oxford (2019), s. 22643.

59 Hubertus von Gall, Die Paphlagonischen Felsgräber: Eine Studie zur kleinasiatischen Kunstgeschichte, Tübingen, 1966, s. 73-82; Peri Johnson, Landscapes of Achaemenid Paphlagonia, University of Pennsylvania, 2010, s. 353; Maya Vassileva, "TheRock-Cut Monuments of Phrygia, Paphlagonia and Thrace: A Comparative Overview”. (ed.) G.R. Tsetskhladze, The Black Sea, Paphlagonia,Pontus and Phrygia in Antiquity: Aspects of Archaeology and Ancient History (BAR International Series 2432), Oxford (2012), s.245; Vassileva, "Phrygia and the southern Black Sea littoral", (ed.) G. R. Tsetskhladze-A. Avram-J. F. Hargrave, The Danubian Lands Between the Black, Aegean and Adriatic Seas (7th Century $B C-10$ th Century AD) (Proceedings of the Fifth International Congress on Black Sea Antiquities, Belgrade, 17-21 September 2013), Oxford (2015), s. 93-94; Yıldırım “Gökbel Köyü Hamas Kıranı Tümülüsü”, Hitit Üniversitesi Sosyal Bilimler Enstitüsü Dergisi Sayn 2, (2018), s. 1307.

60 Alexandru Avram, "Two Phrygian Gods between Phrygia and Dacia", Colloquium Anatolicum 15, (2016), s. 70-83; Christian Marek, Stadt, Ära und Territorium in Pontus-Bithynia und Nord-Galatia, 
kültü olmasının temelinde buradaki yerel kültürlerle olan güçlü etkileşim vardır. $\mathrm{Bu}$ kültün etkilerine kentin Roma Dönemine tarihlendirilen sikkelerinde de sıkça rastlanılmaktadır (Fig. 19) ${ }^{61}$. Kentin Koloni Çağı buluntuları arasında ortaya çıkarılan Phryg seramiği ve Phryg yazıtlarını da bu bağlamda değerlendirmek gerekir.

Tieion akropolünden Güney Karadeniz'deki Grek Kolonizasyonu'nun J. Boardmann, G. R. Tsetskhladze gibi birçok bilim insanı tarafından öne sürülen MÖ 7. yüzylın üçüncü çeyreğinde, Miletos'un önderliğinde gerçekleştiği fikrini doğrular çok sayıda bulgu elde edilmiştir ${ }^{62}$. Bununla birlikte Geç Geometrik dönem at figürinleri ile oldukça benzeşen siyah firnisli at figürini gibi tartışmalı bulgular da mevcuttur. Fakat Akropolde açlan tüm açmalarda Grek Koloni Çağı'nı işaret eden buluntuların neredeyse hepsi MÖ 7. ve 6. yüzylllara tarihlendirilmektedir. Bölgeye gelen Grekler’in Koloni Çağı'ndaki gibi sistematik olmasa da yerleşim öncesi keşif gezileri gibi öncü girişimleri de söz konusu olabilir63. Halys havzasından elde edilen bulgular, Grekler’in MÖ 7. yüzyll öncesinde de Karadeniz ile bir şekilde ilişkide olduğunu göstermektedir ${ }^{64}$.

Istanbuler Forschungen 39, Tübingen, 1993, s. 509.

61 Bülent Öztürk, "Tios (Zonguldak-Filyos) Antik Kentinde Dinsel İnanışlar ve Kültler/ Religious Belief and Cults in Tios", (ed.) S. Dönmez, Lux ex Ponto Euxino. Studies Presented in Honour of Sümer Atasoy, Ankara (2013b), s. 331-332; Bülent Öztürk, "Bithynia-Paphlagonia Sinırından (Tios veya Hadrianopolis) Bir Yazıt Üzerine Düşünceler, Zeus Syrgastes/Syrgastios Kültü ve Agon’u”, (ed.) M. Arslan ve F. Baz, Arkeoloji, Tarih ve Epigrafinin Arasinda: Prof. Dr. Vedat Çelgin’in 68. Doğum Günü Onuruna Makaleler, Istanbul (2018), s. 722.

62 John Boardmann, "Early Greek Pottery on Black Sea Sites?", Oxford Fournal of Archaeology 10.3, (1991), s. 387-390; John Boardmann, The Greeks Overseas: Their Early Colonies and Trade, London, 1999, s. 245-267; R. Gocha Tsetskhladze, "Greek Penetration of the Black Sea”, (ed.), G. R. Tsetskhladze ve F. De Angelis, The Archaeology of Greek Colonisation: Essays Dedicated to Sir Fohn Boardman, (Oxford University Committee for Archaeology Monograph 40), Oxford (1994), s. 123-126; Tsetskhladze, "The Greek Colonisation" s. 19; Tsetskhladze, "The Scythians: Three Essays" (ed.) G. R. Tsetskhladze, The Black Sea, Greece, Anatolia and Europe in the First Millennium BC (Colloquia Antiqua 1), Leuven/Paris/Walpole, MA (2011), s. 96.

63 Akurgal, "Sinop Kazıları", s. 49.

64 Manolis Manoledakis, "The Early Greek Presence in the Southern Black Sea", (ed.) M. Manoledakis, G.R. Tsetskhladze ve Xydopoulos, Ioannis, Essays on the Archaeology and Ancient History of the Black Sea Littoral, (Colloquia Antiqua 18), Leuven/Paris/Bristol (2018), s. 173-241; LatifeSummerer, "Indigenous Responses to Encounters with the Greeks in Northern Anatolia: The Reception of Architectural Terracottas in the Iron Age Settlements of the Halys Basin". (ed.) P. G. Bilde ve J. H. Petersen, Meetings of Cultures in the Black Sea Region: Between Conflicts and Coexistence, (Black Sea Studies 8), Aarhus (2008), s. 262-267; LatifeSummerer, "Influence of the Greek Pottery on the Late Archaic Architectural Terracottas from North Anatolia". Il Mar Nero 6, (2009), s. 188. 
Tieion akropolünde yürütülen çalışmalar, kentin Orta Çağ mimarisine ait izlerin daha az bulunduğu 3. ve 4. teraslarda devam ettirilecektir. Özellikle sahildeki sarnıç yapısının hemen üztünde bulunan 4. terasın, Grek Koloni Çağı'na ait daha fazla veriyi içinde bulundurduğunu düşünüyoruz. Tieion'un Koloni Çă̆ı verileri henüz çok yenidir. Kazıların ilerlemesi ile birlikte elimizdeki verileri arttırmayı ve Güney Karadeniz’in içinde birçok sorusunu barındıran bu dönemini daha ayrıntılı bir şekilde yorumlamayı umuyoruz. 


\section{KAYNAKLAR}

Akurgal, Ekrem, "Sinop Kazıları", Türk Arkeoloji Dergisi 6.1, (1956), s. 47-61.

Akurgal, Ekrem-Budde Ludwig, Vorläufiger Bericht über die Ausgrabungen in Sinope, TTKY 14, Ankara 1956.

Arsenie, Lucian, "Ceramica lucratâ cu mâna la Tomis - stadiul actual al cercetârilor", Pontica 33-34, (2000-2001), s. 283-298.

Atasoy, Sümer, "Zonguldak - Fiyos (Tios/Tieion/Tios/Tianos/Tieum) Kurtarma Kazısı”, (ed.) İ. Delemen, Prof. Dr. Haluk Abbasoğlu'na 65. Yaş Armağan, istanbul 2008, s. 91-97.

Atasoy, Sümer, "Önsöz/ Forward”, (ed.) S. Atasoy ve Ş. Yıldırım, Tios-Filyos Arkeolojik Kazı Projesi. Zonguldak'ta Bir Antik Kent TIOS, Ankara (2015), s. 1-13.

Atasoy, Sümer, "Tios Kentinin Siyasi Tarihi/ The Political History of Tios", (ed.) S. Atasoy ve Ş. Yıldırım, Tios-Filyos Arkeolojik Kazı Projesi. Zonguldak'ta Bir Antik Kent TIOS, Ankara (2015), s. 15-27.

Atasoy, Sümer-Erpehlivan, Hüseyin, "Tios'da Erken Yerleşmeye Ait Keramikler/ Ceramics from the Early Settlement at Tios", (ed.) S. Atasoy ve Ş. Yıldırım, Tios-Filyos Arkeolojik Kazı Projesi. Zonguldak'ta Bir Antik Kent TIOS, Ankara 2015, s. 202-217.

Atasoy, Sümer-Yıldırım, Şahin, "Filyos-Tios 2009 Yılı Kazısı", KST XXXII/IV, 2011 (Ankara), s. 1-16.

Atasoy, Sümer-Yıldırım, Şahin (ed.), Tios-Filyos Arkeolojik Kazı Projesi. Zonguldak'ta Bir Antik Kent TIOS, Ankara 2015.

Avram, Alexandru, "Two Phrygian Gods between Phrygia and Dacia", Colloquium Anatolicum 15, (2016), s. 70-83.

Bean, George, "Tios", The Princeton Encyclopedia of Classical Sites, Princeton (1979), s. 925.

Boardmann, John, "Early Greek Pottery on Black Sea Sites?", Oxford Fournal of Archaeology 10.3, (1991), s. 387-390.

Boardmann, John, The Greeks Overseas: Their Early Colonies and Trade, London 1999.

Bohen, Barbara, Die Geometrischen Pyxiden, Kerameikos 13, Berlin 1988. 
Bohen, Barbara, "The Boeotian Origin of an Unusual Geometric Vase", The f. Paul Getty Museum Fournal 20, (1992), s. 41-44.

Boysal, Yusuf, "Sinop’un En Eski Buluntuları ve Kolonizasyonu Hakkında", Türk Arkeoloji Dergisi 8.2, (1958), s. 23-29.

Brixhe, Claude-Michel, Lejeune, Corpus des Inscriptions Paleo-Phrygiennes, Paris 1984. Büyüksalih, İsmail-Akçın, Hakan-Sefercik, U. Güneş-Karakış, Serkan-Marangoz, A. Murat, "Batı Karadeniz Sahil Bölgesindeki Filyos Nehri ve Deltasındaki Değişimlerin Zamansal CBS ile İncelenmesi”, Ege Coğrafi Bilgi Sistemleri Çalıştayı, İzmir (2005), s. 1-8.

Coldstream, J. Nicolas, Geometric Greece: 900-700 BC, 2 ${ }^{\text {nd }}$ ed., London 2003.

Cook, R. Manuel, "Fikellura Pottery", Annual of the British School at Athens 34, (1933-34), s. 1-99.

Cook, R. Manuel, "Ionia and Greece in the $8^{\text {th }}$ and $7^{\text {th }}$ Centuries B.C.", $\mathcal{F} H S 66$, (1946), s. 67-98.

Cook, R. Manuel, "The Wild Goat and Fikellura Styles: Some speculations", Oxford Journal of Archaeology 11.3, (1992), s. 255-266.

Cook, R. Manuel-Dupont, Pierre, East Greek Pottery, London and New York, 1998.

Crow, James-Hill, Stephen, "The Byzantine Fortifications of Amastris in Paphlagonia”, Anatolian Studies 45, (1995), s. 251-265.

Cummer, W. Willson, "Iron Age Pottery from Akalan". Mitteilungen des Deutschen ArchäologischenInstituts, Abteilung İstanbul 26, (1976), s. 31-36.

Damyanov, Margarit, "On the Chronology of the Earliest Greek Metallurgy in Apollonia Pontica (Poster presented)", The $19^{\text {th }}$ International Congress of Classical Archaeology-Archaeology and Economy in the Ancient World, (22-26 May 2018), Cologne/Bonn, 2018.

Dimitriu, Suzaria, "Cartierul de locuinte din zona de vest a cetatii, inepoca arhaica Sapaturi 1955-1960", (ed.) E. Conduraci, Histria 2, Bucharest (1960), s. 19-132.

Doonan, Owen-Vural, Hüseyin-Goldman, Andrew-Bauer, Alexander-Rempel, Jane-Sherratt, Suzan-Krotschek, Ulrike-Maranzana, Paolo-Sökmen, Emine, "Sinop Kalesi Archaeological Excavations, 2015-2016 Field Seasons", (ed.) 
S. Steadman ve G. McMahon, The Archaeology of Anatolia: Recent Discoveries, vol. 2, Newcastle-upon-Tyne (2017), s. 178-199.

Dupont, Pierre, "Naturwissenschaftliche Bestimmung der Archaischen Keramik Milets", (ed.) W. Müller-Wiener, Istanbuler Mitteilungen Beiheft 31, Tübingen (1986), s. 57-71.

Ekmen, Hamza-Mercan, Ahmet-Gülden Ekmen-Güney, Ali, “İnönü Mağarası 2017 Yılı Kazıları”, KST XXXX/II, Ankara (2019), s. 271-292.

Esen, İzet, "Antik Tios/Tieion/Villaios (Filyos) Kenti", Anadolu Medeniyetleri Müzesi 2002 Yillı̆ğ, Ankara (2003), s. 196-224.

Henrickson, Robert, "Continuity and Discontinuity in the Ceramic Tradition of Gordion during the Iron Age". (ed.) D. French, ve A. Çilingiroğlu, Anatolian Iron Ages 3 (Proceedings of the Third Anatolian Iron Ages Colloquium held at Van, 6-12 August 1990) (British Institute of Archaeology at Ankara, Monograph 16), London (1994), s. 95-129.

Henrickson, Robert, "The Local Potter's Craft at Phrygian Gordion", (ed.) L. Kealhofer, The Archaeology of Midas and the Phrygians: Recent Work at Gordion, Philadelphia (2005), s. 124-135.

Henrickson, Robert-Vandiver, Pamela-Blackman, James, "Lustrous Black Fine Ware at Gordion, Turkey: A Distinctive Sintered Slip Technology", (ed.) P. B. Vandiver, M. Goodway, ve J. L. Mass, Materials Issues in Art and Archaeology VI (Symposium held November 26-30, 2001, Boston, Massachusetts, Materials Research Society Symposia Proceedings 712), Warrendale, PA (2002), s. 391-400.

Hubertus, von Gall, Die Paphlagonischen Felsgräber: Eine Studie zur kleinasiatischen Kunstgeschichte, Tübingen, 1966.

Johnson, Peri, Landscapes of Achaemenid Paphlagonia, University of Pennsylvania, 2010.

Jones, A. H. Martin, The Cities of the Eastern Roman Provinces, $2^{\text {nd }}$ ed., Amsterdam, 1983.

Jones, Richard, E., Greek and Cypriot Pottery, A Review of Scientific Studies, British School at Athens, Fitch Laboratory Occasional Paper 1, Athens, 1986.

Kealhofer, Lisa-Grave, Peter-Marsh, Ben-Steadman, Sharon-Gorny, L. Ronald- 
Summers, D. Geoffrey, "Patterns of Iron Age Interaction: Three sites in Yozgat Province”, Anatolian Studies 60, (2010), s. 71-92.

Kerschner, Michael-Mommsen, H.-Akurgal, Meral-Niemeier, W. Dietrich, Töpferzentren der Ostagais: Archaometrische und archaologische Untersuchungen zur Mykenischen, geometrischenund archaischen Keramik aus Fundorten in Westkleinasien, Ergänzungshefte zu den Jahresheften des Österreichischen Archaologischen Institutes in Wien 3, Vienna 2002.

Kerschner, Michael- Schlotzhauer, Udo, "A new Classification System for East Greek Potter", Ancient West and East 4.1, (2005), s. 1-56.

Küçükali, Serhat, "Forecasting the river discharge, thermal and sediment load characteristics: A case study", (ed.) M. S. Altınakar ve diğerleri, River Flow 2008 (Proceedings of the International Conference on Fluvial Hydraulics, Çeşme, Izmir, Iurkey, 3-5 September 2008), Ankara (2008), s. 1975-1981.

Lafl, Ergün-Gülseren, K. Şahin, "Iron Age and Hellenistic Ceramics from Southwestern Paphlagonia”, Archaeology and Science 7, (2012), s. 9-166.

Lafl, Eergün-Gürselen K. Şahin-Patacı, Sami, "Iron Age Ceramics from Southwestern Paphlagonia", Anatolia Antiqua 21, (2013), s. 33-68.

Manoledakis, Manolis,. "The Early Greek Presence in the Southern Black Sea", (ed.) M. Manoledakis, G.R. Tsetskhladze ve Xydopoulos, Ioannis, Essays on the Archaeology and Ancient History of the Black Sea Littoral, (Colloquia Antiqua 18), Leuven/Paris/Bristol (2018), s. 173-241.

Marchenko, Konstantin.Konstantinovich, Varvary v sostave naseleniya Berezani i Ol'vii, vo vtoroi polovine VI - pervoi polovine IV. do n.e.: po materialam lepnoi Keramiki, Leningrad 1988.

Marek, Christian, Stadt, Ara und Territorium in Pontus-Bithynia und Nord-Galatia, Istanbuler Forschungen 39, Tübingen 1993.

Marek, Christian, Pontus et Bithynia: Die römischen Provinzen im Norden Kleinasiens, Mainz 2003.

Marek, Christian, In the Land of a Thousand Gods: A History of Asia Minor in the Ancient World, Princeton/Oxford 2016.

Matthews, Roger-Glatz, Claudia, At empires' edge; Project Paphlagonia, regional survey in North central Turkey, British Institute of Archaeology at Ankara, London 2009. 
Mitten, D. Gordon, "The Earliest Greek Sculptures in the Museum", Boston Museum Bulletin, 339, (1967), s. 4-18.

Muscarella, O. White, "Phrygian or Lydian?", Fournal of Near Eastern Studies 30, (1971), s. 49-63.

Öztürk, Bülent, "Kuruluşundan Bizans Devri Sonuna Kadar Tios Antik Kenti/ The ancient city of Tios from its establishment till the end of the Byzantine Period", Arkeoloji Sanat 128, (2008), s. 63-78.

Öztürk, Bülent, Küçükasya'nın Batı Karadeniz Kıyısında Bir Antik Kent: Tios (Tieion), Marmara University, (Ph. D Dissertation), İstanbul 2012.

Öztürk, Bülent, "The History of Tieion/Tios (Eastern Bithynia) in the light of Inscriptions", (ed.) Manoledakis, M. Exploring the Hospitable Sea (Proceedings of the International Workshop on the Black Sea in Antiquity held in in Thessaloniki, 21-23 September 2012), (BAR International Series 2498), Oxford (2013a), s. 147-164.

Öztürk, Bülent, "Tios (Zonguldak-Filyos) Antik Kentinde Dinsel İnanışlar ve Kültler/ Religious Belief and Cults in Tios", (ed.) Ş. Dönmez, Lux ex Ponto Euxino. Studies Presented in Honour of Sümer Atasoy, Ankara (2013b), s. 331-346.

Öztürk, Bülent, "Bithynia-Paphlagonia Sınırından (Tios veya Hadrianopolis) Bir Yazıt Üzerine Düşünceler, Zeus Syrgastes/Syrgastios Kültü ve Agon’u”, (ed.) M. Arslan ve F. Baz, Arkeoloji, Tarih ve Epigrafi'nin Arasında: Prof. Dr. Vedat Çelgin'in 68. Doğum Günü Onuruna Makaleler, Istanbul (2018), s. 717740 .

Öztürk, Bülent-Sönmez, F. İhsan, "Batı Karadeniz'de Bir Antik Kent Kazısı: Tios (Filyos)/ Tios (Filyos): Excavations at an ancient city on the western Black Sea Region of Turkey", Arkeoloji Sanat 127, (2008), s. 133-146.

Panayotova, Krastina-Damyanov, Margarit-Stoyanova, Daniela-Bogdanova, Teodora, "Apollonia Pontica: The Archaic Temenos and Settlement on the Island of St. Kirik" (Poster presented), (ed.) J. M. Alvarez, T. Nogales ve I. Rod, Centre and Periphery in the Ancient World, (Proceedings of the XVIII International Congress of Classical Archaeology I Merida 13.-17. May 2013), 2014.

Robert, Louis, Études Anatoliennes: Recherches sur les inscriptions grecques de l'Asie Mineur, Paris 1937. 
Ruge, Walther, “Tieion”, RE VI A.1, (1936), s. 856-862.

Sams, G. Kenneth, The Early Phrygian Pottery, Gordion Excavations 4.1-2; University Museum Monograph 79, Philadelphia 1994.

Schlotzhauer, Udo, "Ausgewählte Beispiele ostgriechischer Keramik aus Naukratis im Blickwinkel neuer Forschungen", (ed.) U. Höckmann, ve D. Kreikenbom, Naukratis: Die Beziehungen zu Ostgriechenland, Ägypten und Zypern in archaischer Zeit (Akten der Table Ronde Mainz, November 1999), Möhnesee (2001), s. $111-125$.

Sezgin, Yusuf, Arkaik Dönem İonia Üretimi Ticari Amphoralar, Istanbul, 2012.

Solovyov, L. Sergei, Ancient Berezan: The Architecture, History and Culture of the First Greek Colony in the Northern Black Sea, (ed.)J. Boardman ve G.R. Tsetskhladze, (Colloquia Pontica 4), Leiden/Boston/Cologne, 1999.

Stewart, S. Marie, Gordion After the Knot: Hellenistic Pottery and Culture, (Ph.D. dissertation), University of Cincinnati, Cincinati, 2010.

Summerer, Latife, "Indigenous Responses to Encounters with the Greeks in Northern Anatolia: The Reception of Architectural Terracottas in the Iron Age Settlements of the Halys Basin". (ed.) P. G. Bilde ve J. H. Petersen, Meetings of Cultures in the Black Sea Region: Between Conflicts and Coexistence, (Black Sea Studies 8), Aarhus (2008), s. 263-286.

Summerer, Latife, "Influence of the Greek Pottery on the Late Archaic Architectural Terracottas from North Anatolia”. Il Mar Nero 6, (2009), s. 187202.

Tolstikov, P. Vladimir, "Pantikapej - Stolitsa Bospora", (ed.) G. A Koshelenko, Ocherki Arkheologii Bospora, (1992), s. 45-99.

Toncheva, Goranka, "Arhaichiya materiali ot Odesos", Izvestiya na Arheologicheskiya Institut 30.1, (1967), s. 57-180.

Toteva, G. Dechkova, Local Cultures of Late Achaemenid Anatolia, (Ph.D. dissertation), University of Minnesota, 2007.

Treister, Y. Mikhail, "Excavations at Pantikapaion, Capital of the Kingdom of Bosporus. Old Finds, Recent Results and some New Observations", (ed.) A. J. Todd-D. Komini-Dialeti-D. Hatzivassihou, Greek Archaeologywithout Frontiers, Athens 2002, s. 151-172. 
Tsetskhladze, R. Gocha, "Greek Penetration of the Black Sea", (ed.), G. R. Tsetskhladze ve F. De Angelis, The Archaeology of Greek Colonisation: Essays Dedicated to Sir Fohn Boardman, (Oxford University Committee for Archaeology Monograph 40), Oxford (1994), s. 111-135.

Tsetskhladze, R. Gocha, "The Greek Colonisation of the Black Sea Area: Stages, Models, and Native Population" (ed.) G. R. Tsetskhladze, The Greek Colonisation of The Black Sea Area: Historical Interpretation of Archaeology, (Historia Einzelschriften 121), Stuttgart (1998), s. 9-68.

Tsetskhladze, R. Gocha, "Note on semi-pithouses and handmade pottery from Gordion", (ed.) A. Avram ve M. Babes, Civilisation grecque et cultures antiques périphériques: Hommage à Petre Alexandrescu à son 70e anniversaire, Bucharest (2000), s. $165-170$.

Tsetskhladze, R. Gocha, "On the Earliest Greek Colonial Architecture in the Pontus", (ed.) C. J. Tuplin, Pontus and the Outside World. Studies in Black Sea History, Historiography and Archaeology, (Colloquia Pontica 9), Leiden/Boston (2004), s. 225-278.

Tsetskhladze, R. Gocha, Karadeniz'in Tarih ve Arkeolojisi Üzerine: Arkaik ve Klasik Dönemlerde Karadeniz'de Ticaret: Bazı Gözlemler; İskit ile Thrak Kral ve Seçkin Mezarlannı Kim İnşa Etti?; Anayurtlan Dışındaki İoniahlar, Istanbul, 2005a.

Tsetskhladze, R. Gocha, "Early Iron Age Societies of the Black Sea region and Anatolia: Some Observations", (ed.) G. Darbyshire ve A. Çilingiroğlu, Anatolian Iron Ages 5 (Proceedings of the Fifth Anatolian Iron Ages Colloquium held at Van, 6-10 August 2001) (British Institute of Archaeology at Ankara Monograph 31), London (2005b), s. 211-216.

Tsetskhladze, R. Gocha, "The Scythians: Three Essays” (ed.) G. R. Tsetskhladze, The Black Sea, Greece, Anatolia and Europe in the First Millennium BC (Colloquia Antiqua 1), Leuven/Paris/Walpole, MA (2011), s. 95-139.

Vachtina, J. Marina, "Archaic Buildings of Porthmion", (ed.) P.G. Bilde, J. M. Højte ve V. F. Stolba, The Cauldron of Ariantas: Studies presented to A.N. Sčeglov on the Occasion of his 70 Birthday (Black Sea Studies 1), Aarhus (2003), s. 37-54.

Vassileva, Maya, "The Rock-Cut Monuments of Phrygia, Paphlagonia and Thrace: A Comparative Overview". (ed.) G.R. Tsetskhladze, The Black Sea, Paphlagonia,Pontus and Phrygia in Antiquity: Aspects of Archaeology and Ancient History (BAR International Series 2432), Oxford (2012), s. 243-252. 
Vassileva, Maya, "Phrygia and the southern Black Sea littoral", (ed.) G. R. Tsetskhladze, A. Avram ve J. F. Hargrave, The Danubian Lands Between the Black, Aegean and Adriatic Seas ( $7^{\text {th }}$ Century BC-10 $10^{\text {th }}$ Century AD) (Proceedings of the Fifth International Congress on Black Sea Antiquities, Belgrade, 17-21 September 2013), Oxford (2015), s.91-96.

Voight, M. Mary, "Excavations in Gordion 1988-1989; the Yassihöyük Stratigraphic Sequence", (ed.) D. H. French, ve A. Çilingiroğlu, Anatolian Iron Ages 3 (Proceedings of the Third Anatolian Iron Ages Colloquium held at Van, 6-12 August 1990) (British Institute of Archaeology at Ankara, Monograph 16), London (1994), s. 265-293.

Voyatzis, Mary, "Votive riders seated side-saddle at early Greek sanctuaries", Annual of the British School at Athens 87, (1992), s. 259-279.

Ylldırım, Şahin, "Tios Roma Tiyatrosu/ The Roman Theater of Tios". (ed.) S. Atasoy ve Ş. Yıldırım, Tios-Filyos Arkeolojik Kazı Projesi. Zonguldak'ta Bir Antik Kent TIOS, Ankara (2015), s. 271-295.

Yıldırım, Şahin, "Tios-Tieion: Söylenecek Çok Önemli Bir Şeyi Olmayan Kent", Trakya Üniversitesi Edebiyat Fakültesi Dergisi, 7/14, (2017a), s. 206-242.

Yıldırım, Şahin, "Tios-Tieion 2015 Yılı Kazı Çalışmaları”, KST XXXVIII/I, Ankara (2017b), s. 465-478.

Yıldırım, Şahin, "Gökbel Köyü Hamas Kıranı Tümülüsü”, Hitit Üniversitesi Sosyal Bilimler Enstitüsü Dergisi, S. 2, (2018), s. 1295-1319.

Yıldırım, Şahin, "A Great Tumulus from Paphlagonia", (ed.) G. R. Tsetskhladze ve S. Atasoy, Settlements and Necropoleis of the Black Sea and its Hinterland in Antiquity (Selected Papers from the Third International Conference 'The Black Sea in Antiquity and Tekkeköy: An Ancient Settlement on the Southern Black Sea Coast', 27-29 October 2017, Tekkeköy, Samsun), Oxford (2019), s.226-43.

Young, Rodney, Late Geometric Graves and a Seventh-Century Well in the Agora, (Hesperia Suppl. 2), Athens, 1939.

Young, Rodney, "Old Phrygian Inscriptions from Gordion: Toward a History of the Phrygian Alphabet”, Hesperia 38, (1969), s. 252-296.

Zolotarev, I. Miron, "Ранние этапы градостроительствав Херсонесе Таврическом" (Early stages of city building in Taurian Chersonessos), Chersonesskïsbornik 9, (1998), s. 26-35. 


\section{EKLER}

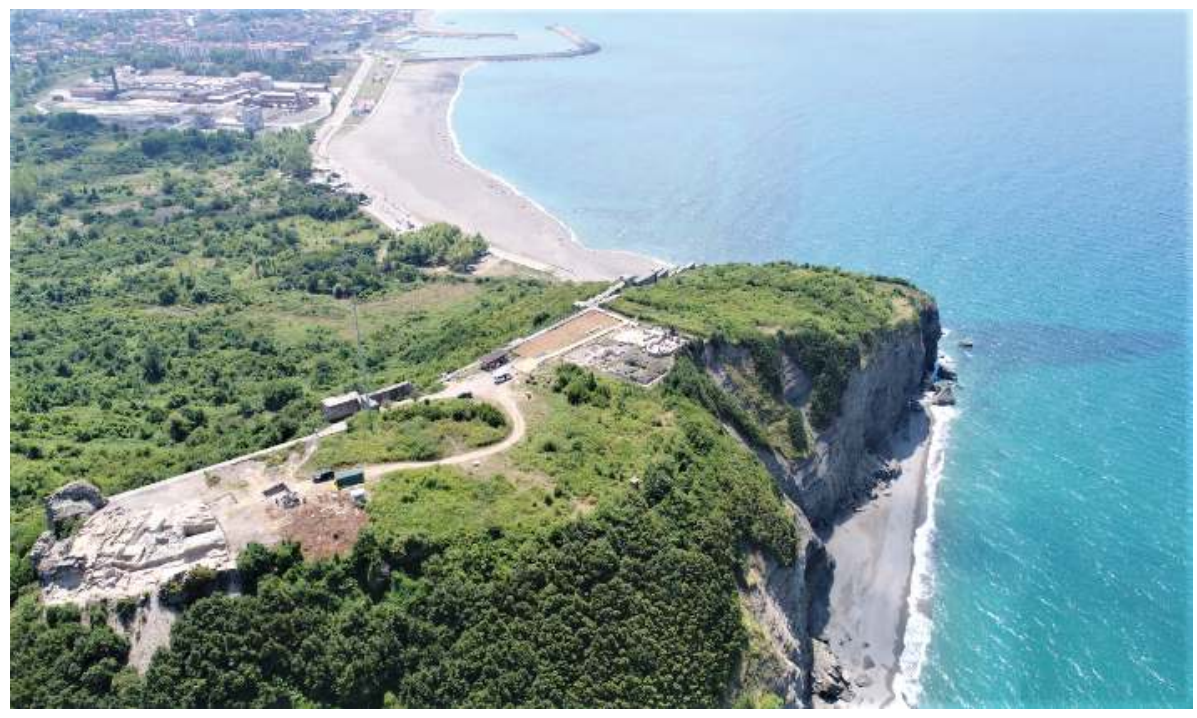

Figür 1: Tieion Akropolisinin doğudan görünümü.

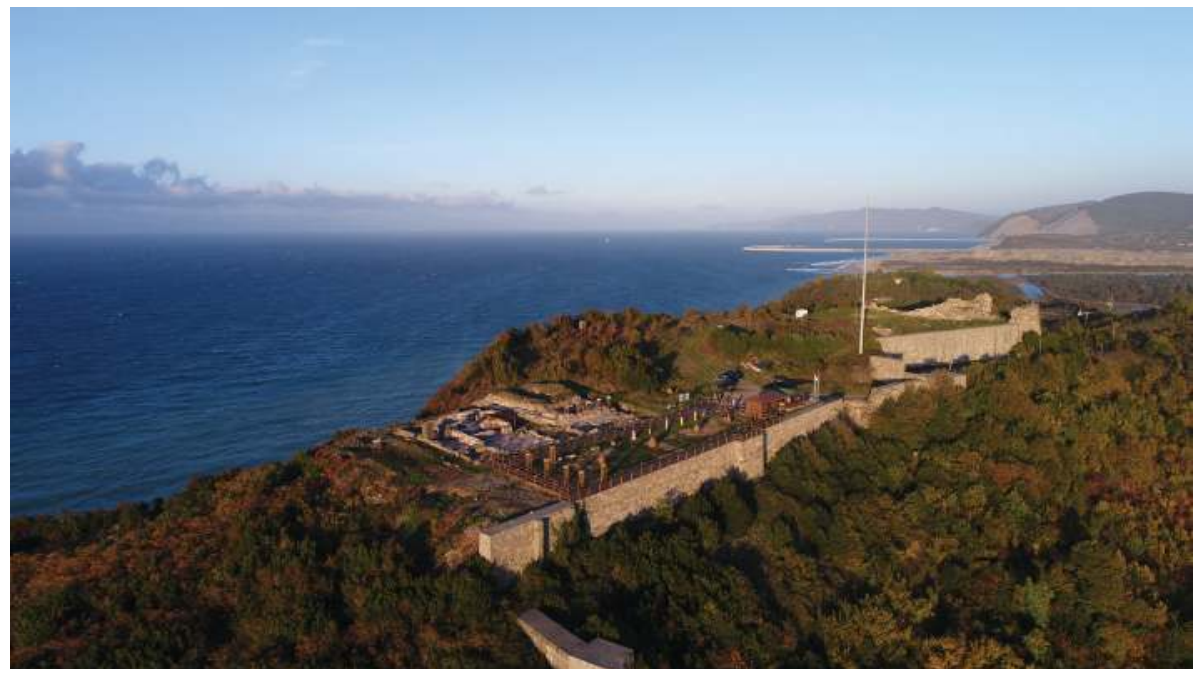

Figür 2: Tieion Akropolisi ve Billaios Nehri’nin batıdan görünümü. 


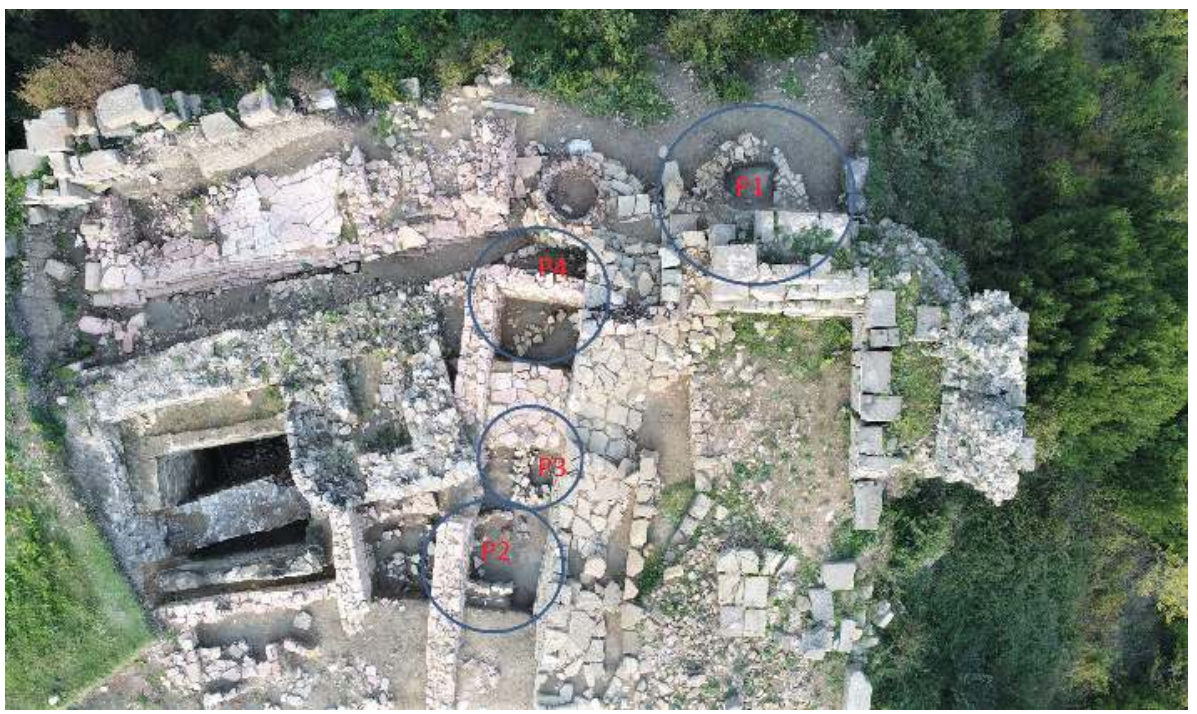

Figür 3: Akropolde bulunan Arkaik Dönem konutlarının konumları.

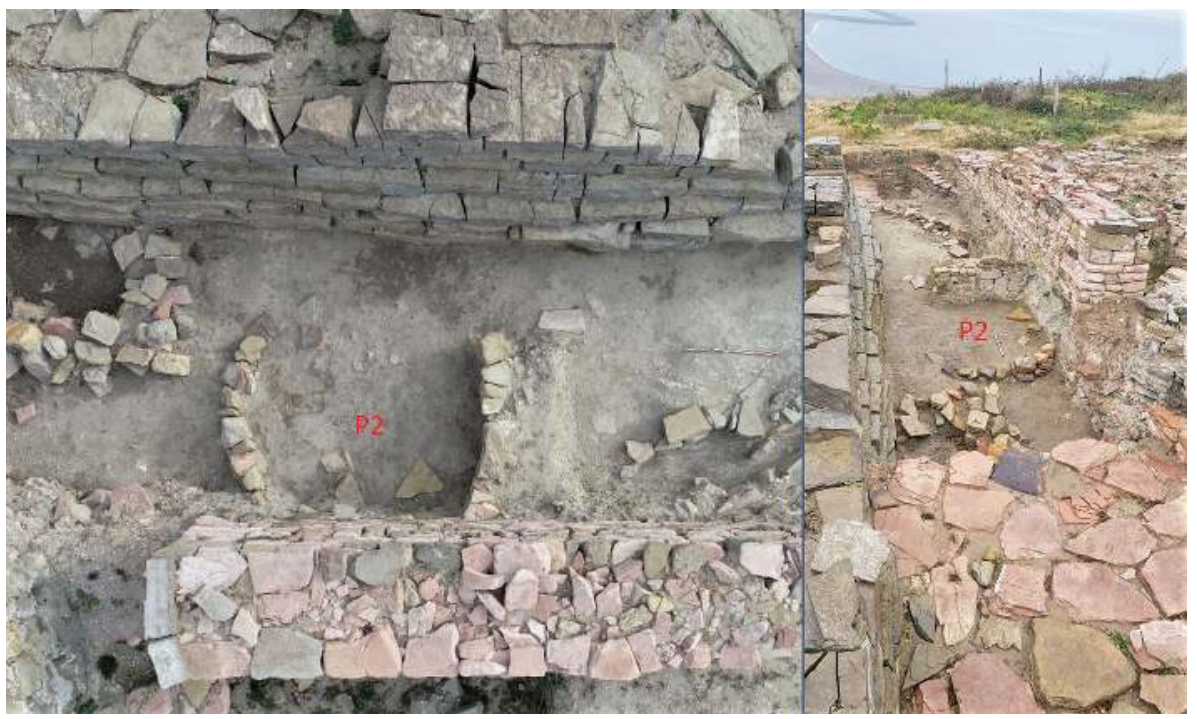

Figür 4: Yuvarlak planlı konutlardan P2 yapısı.

Belleten, Ağustos 2021, Cilt: 85/Sayı: 303; 383-422 


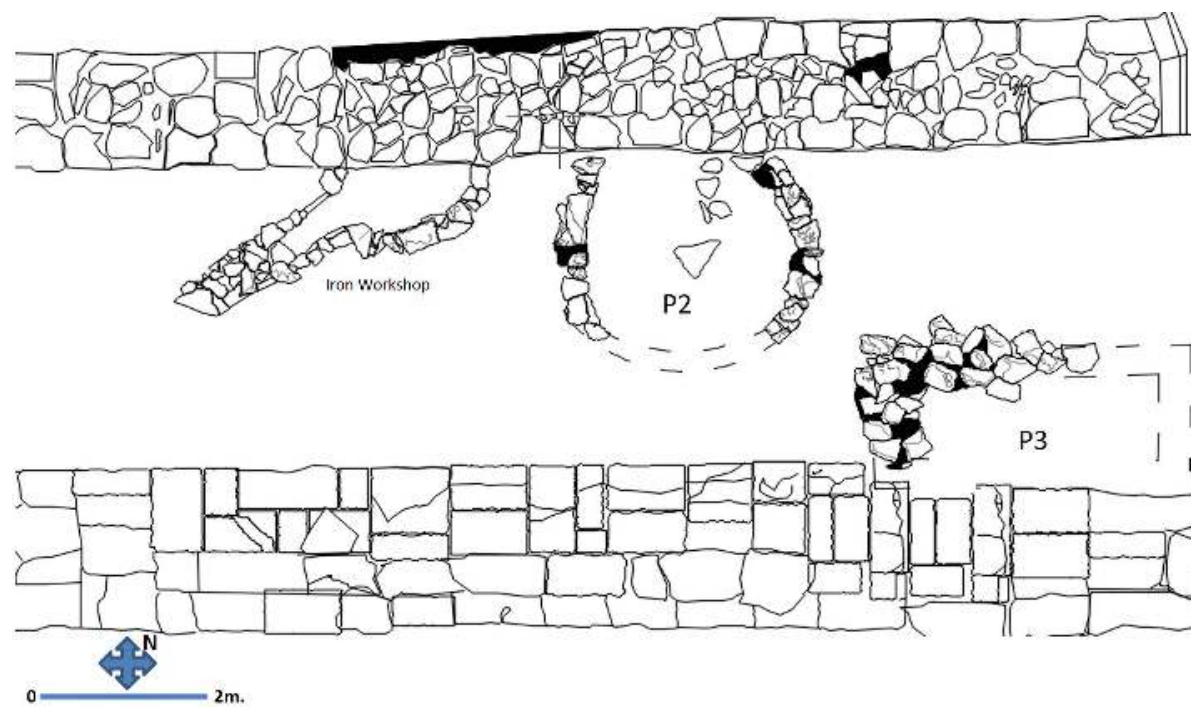

Figür 5: P2 ve P3 konutlarının planları.

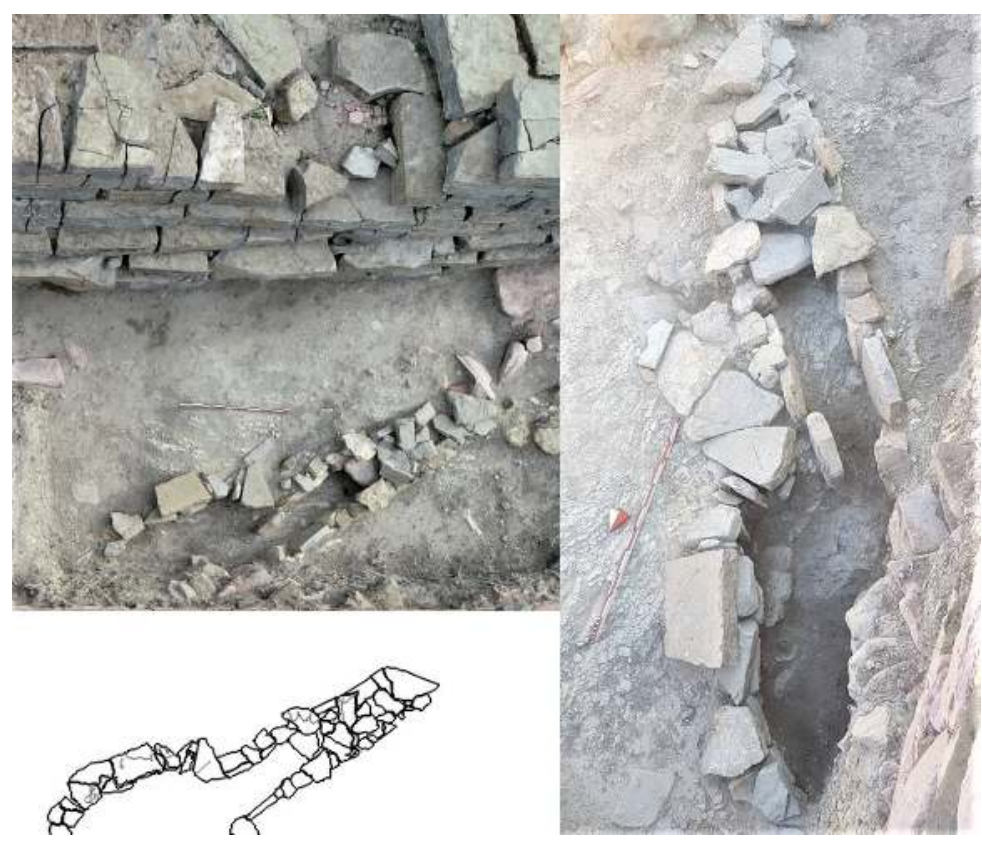

Figür 6: Arkaik Dönem’e tarihlendirilen demir ocă̆ı. 


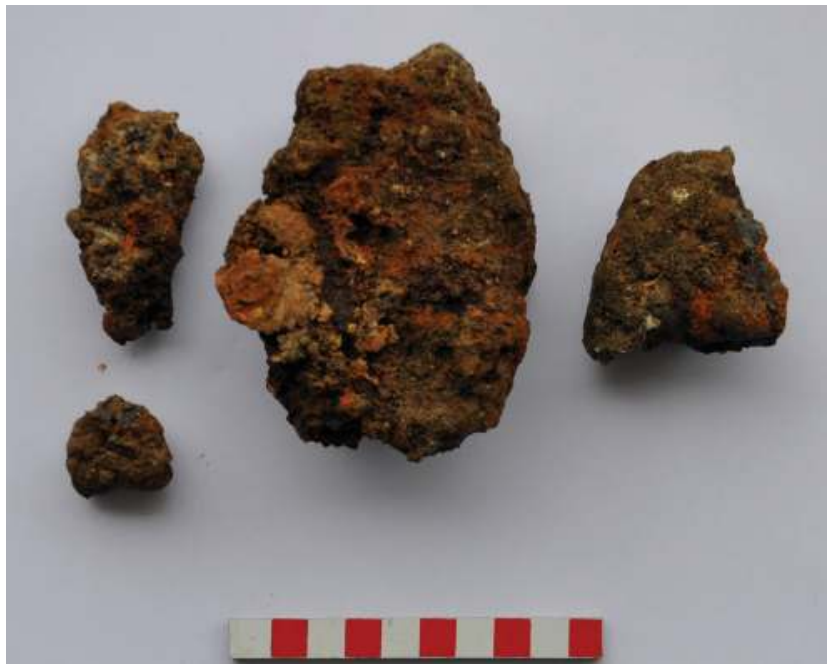

Figür 7: Arkaik Dönem ocağında bulunan demir curufları.

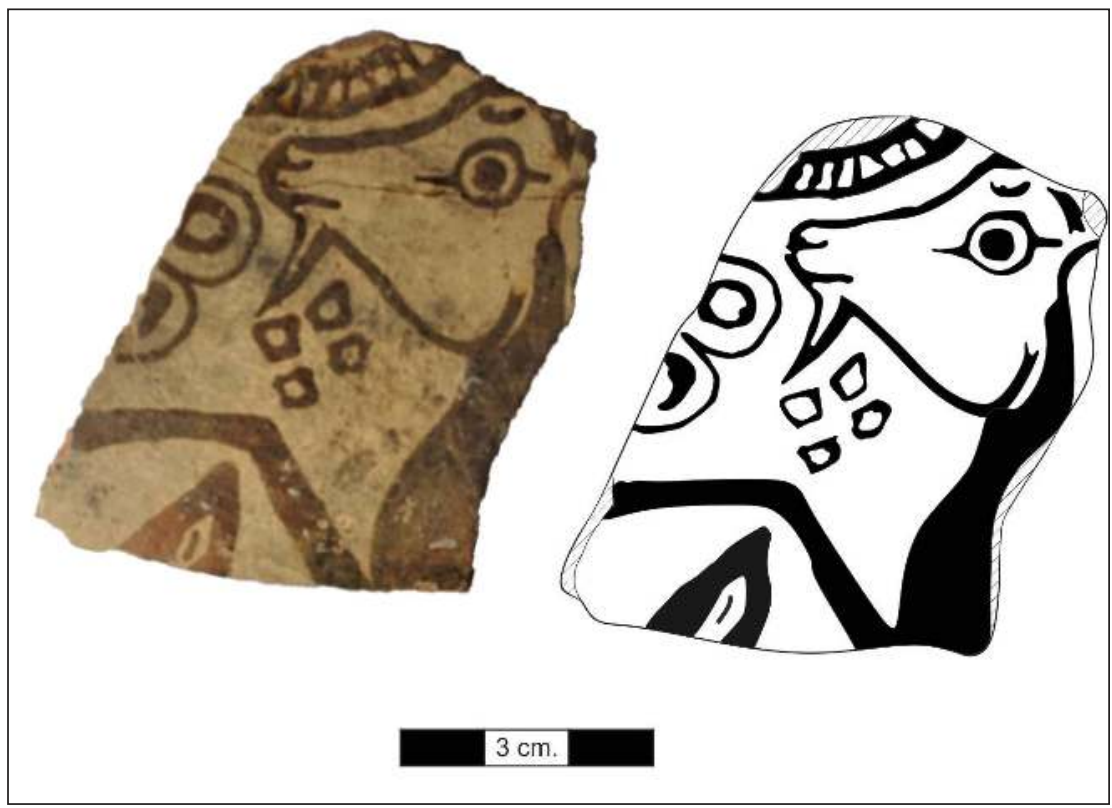

Figür 8: Miletos Orta Yaban Keçisi 2 evresi'ne tarihlendirilen seramik parçası. 


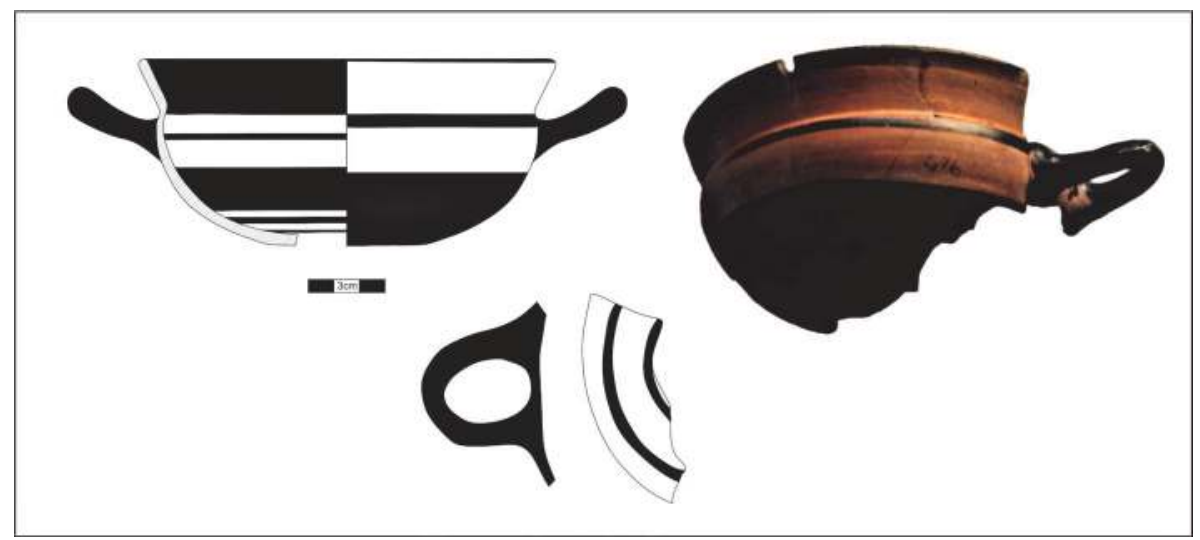

Figür 9: Arkaik Dönem konutlarında bulunan bir İonia kylixi.

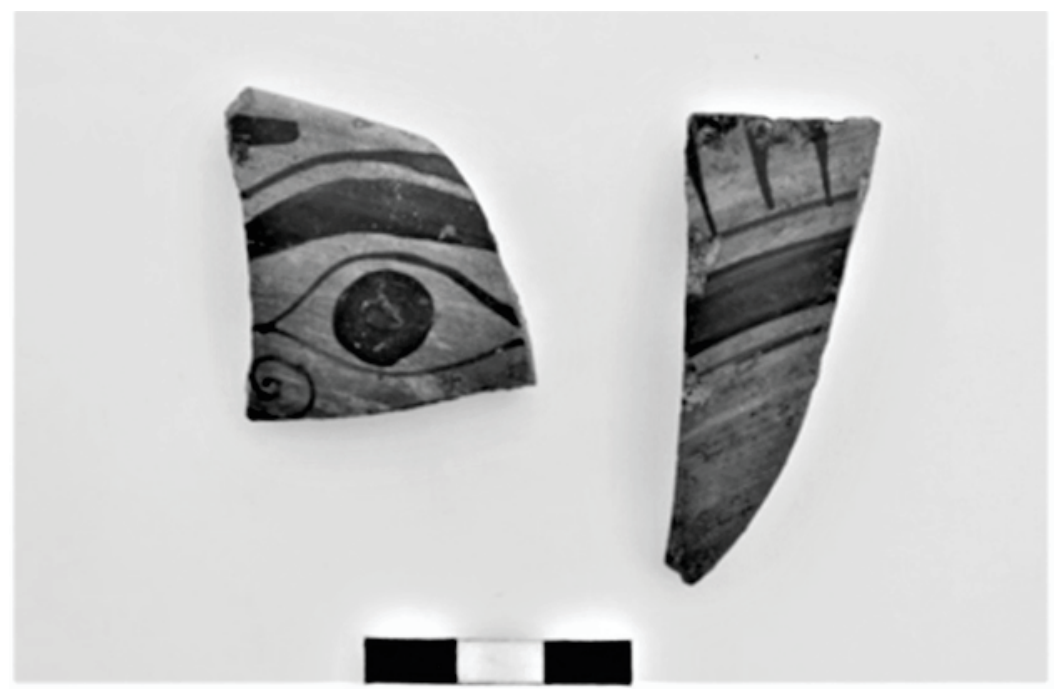

Figür 10: P1 yapısının 2. evresinde bulunan gözlü kylix örneği. 


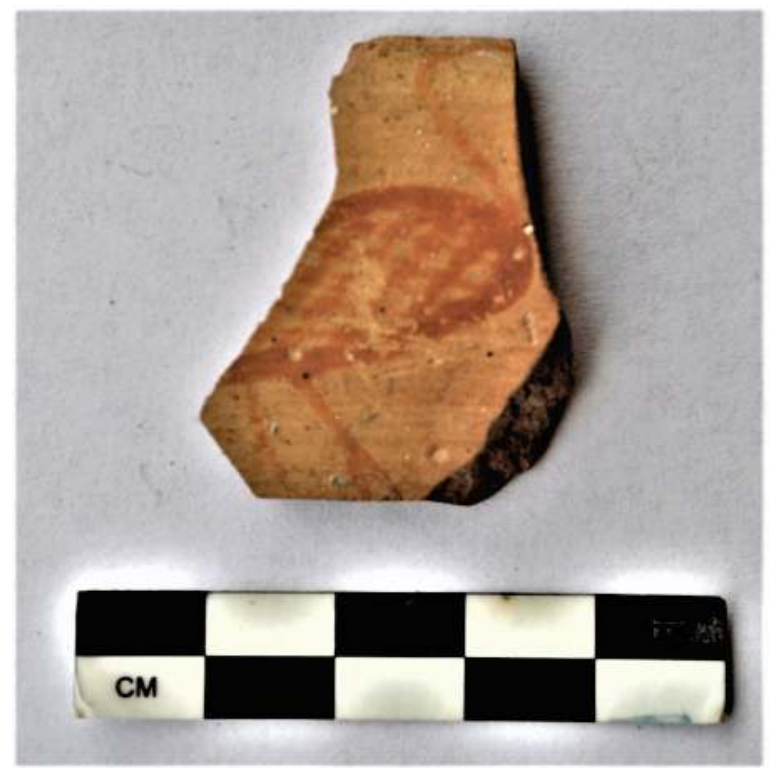

Figür 11: Akropolde bulunan Arkaik Dönem kuşlu kase parçası.

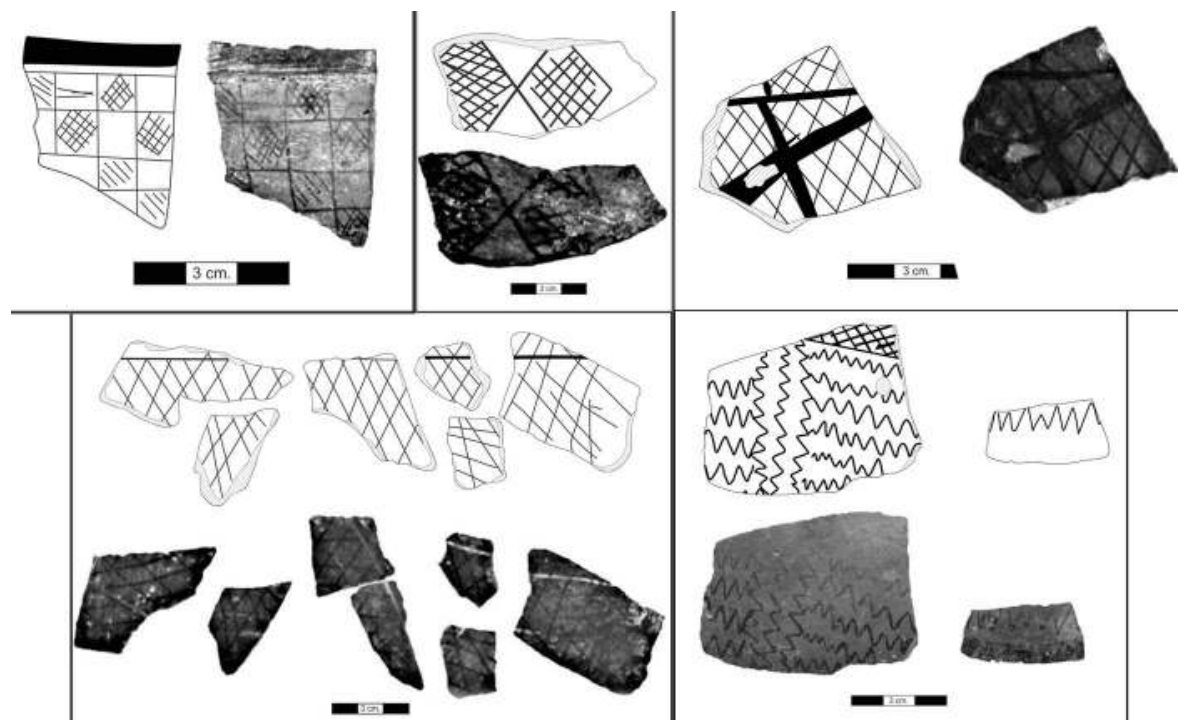

Figür 12: Arkaik Dönem tabakalarında bolca karşımıza çıkan yerel Phryg seramiği. 


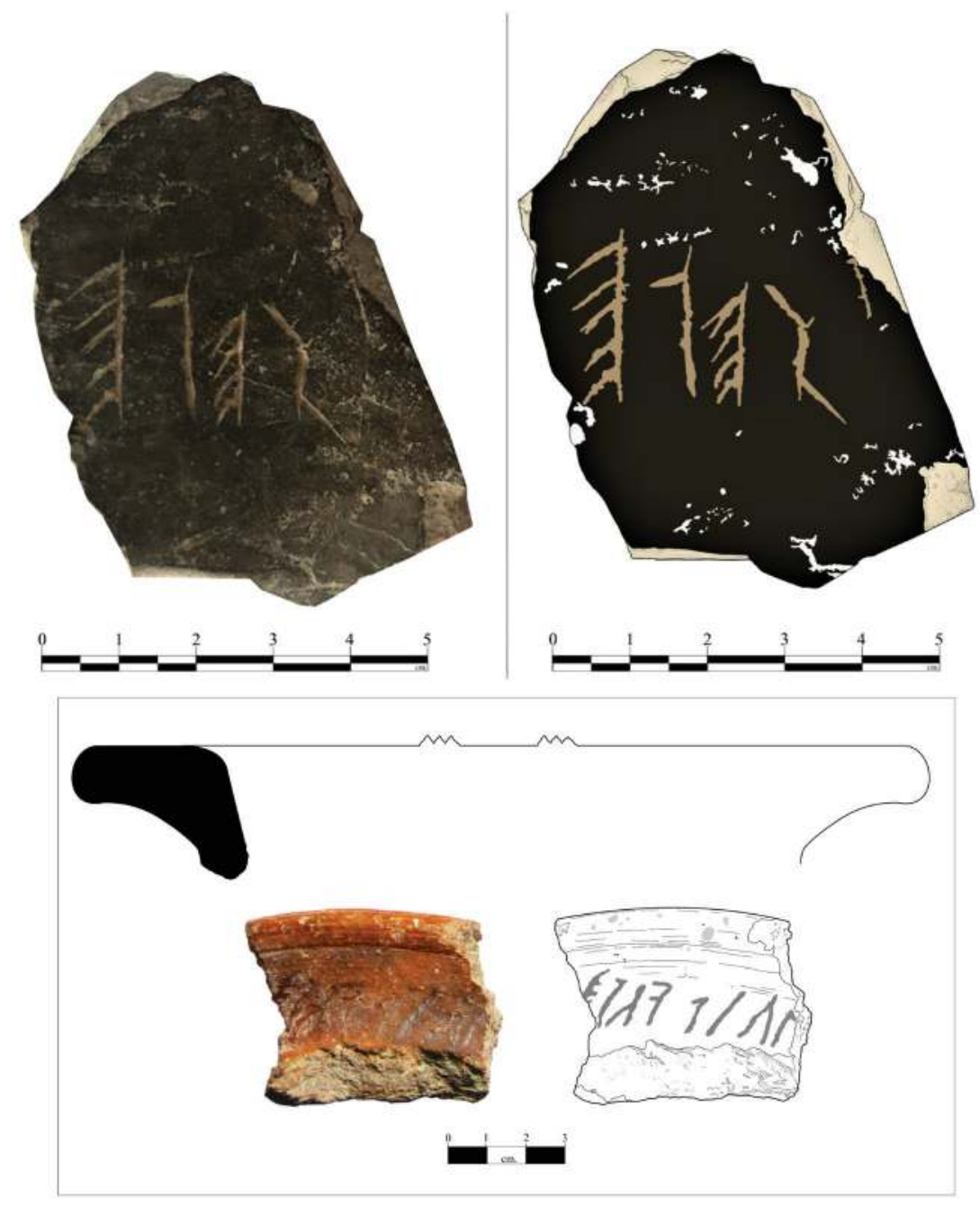

Figür 13: Üzerinde Phrygce yazıtlar bulunan pişmiş toprak kap örnekleri. 


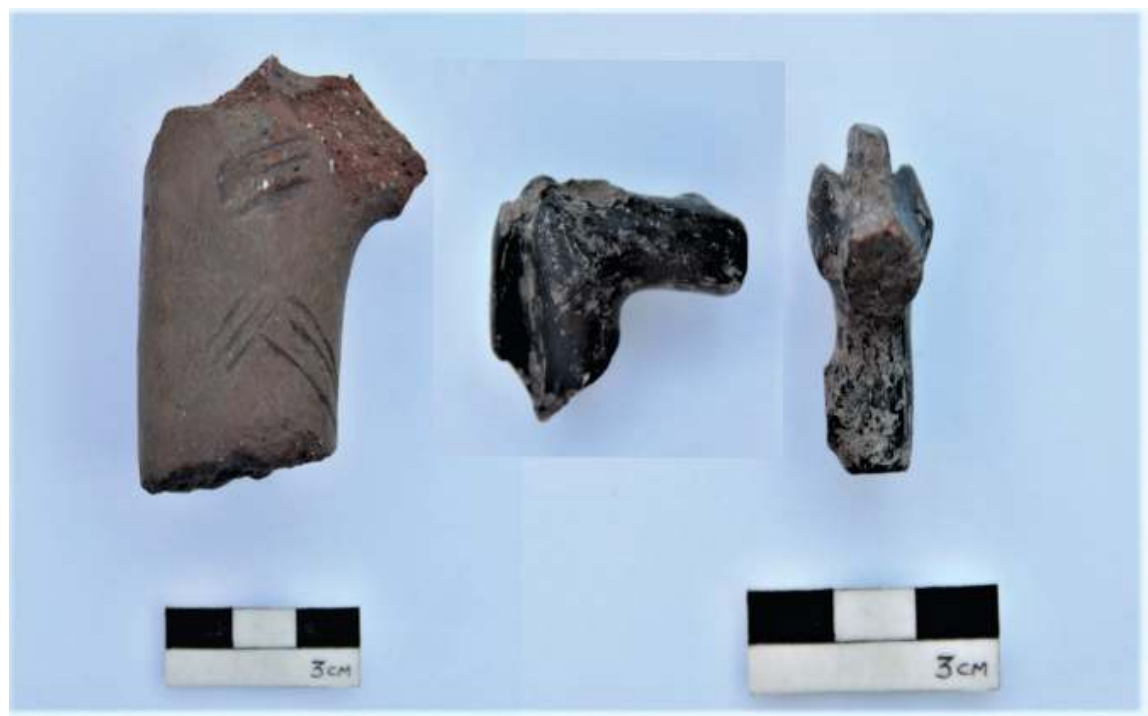

Figür 14: P1 yapısında bulunan pişmiş toprak at figürini parçaları.

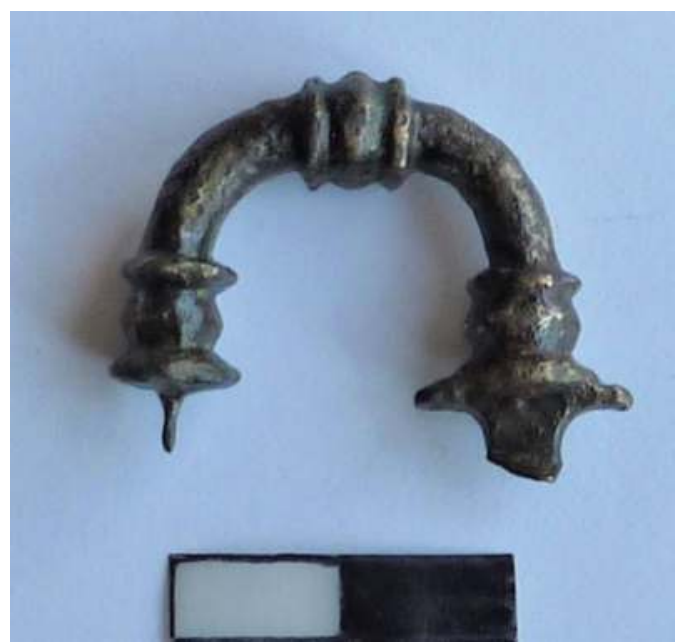

Figür 15: Gökçebey, Üçburgu'da nehir limanı kazıları sırasında bulunan bronz Phryg fibulası. 


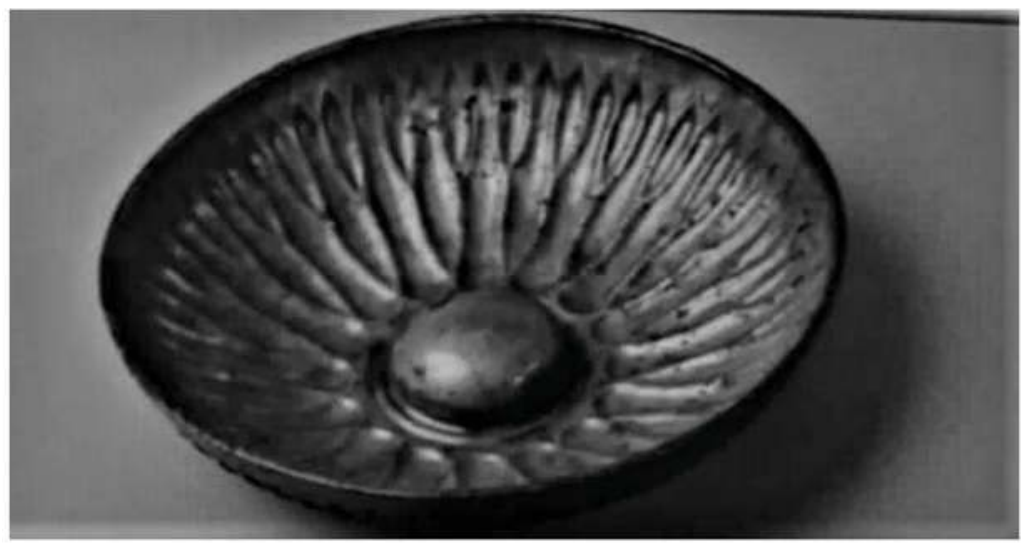

Figür 16: Gökçebey’de bir tümülüsde bulunmuş omphaloslu bronz kase.

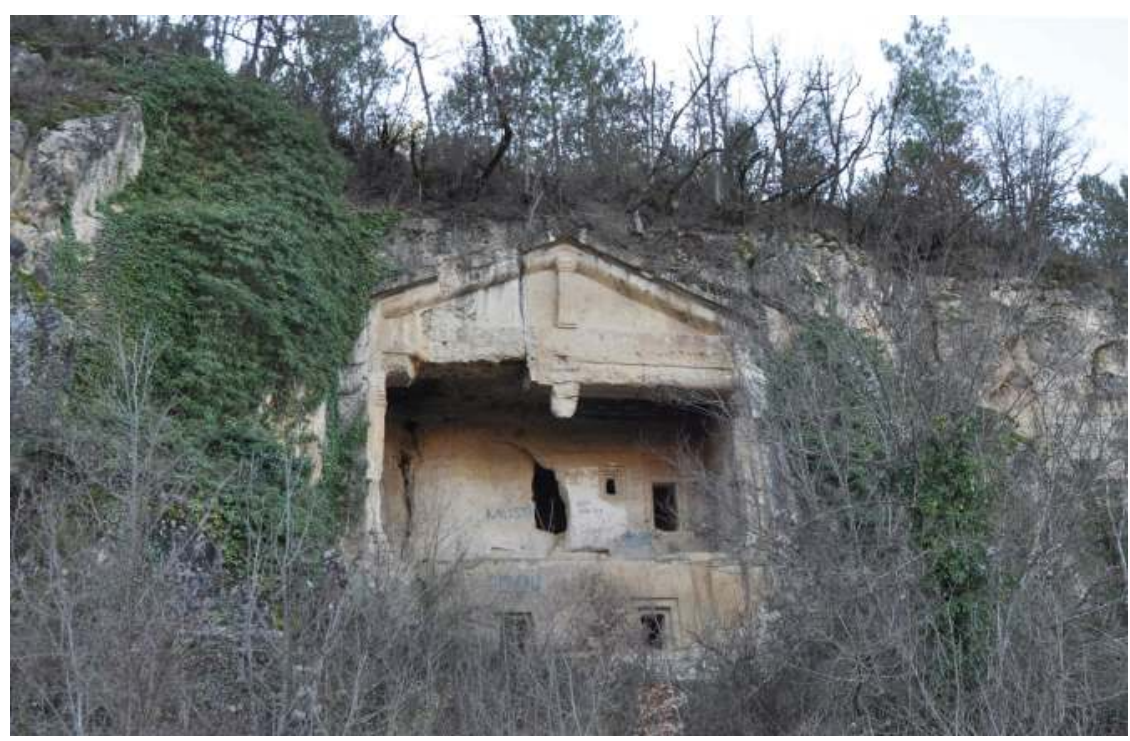

Figür 17: Karakoyunlu Köyü Gerdekboğazı kaya mezarı. 


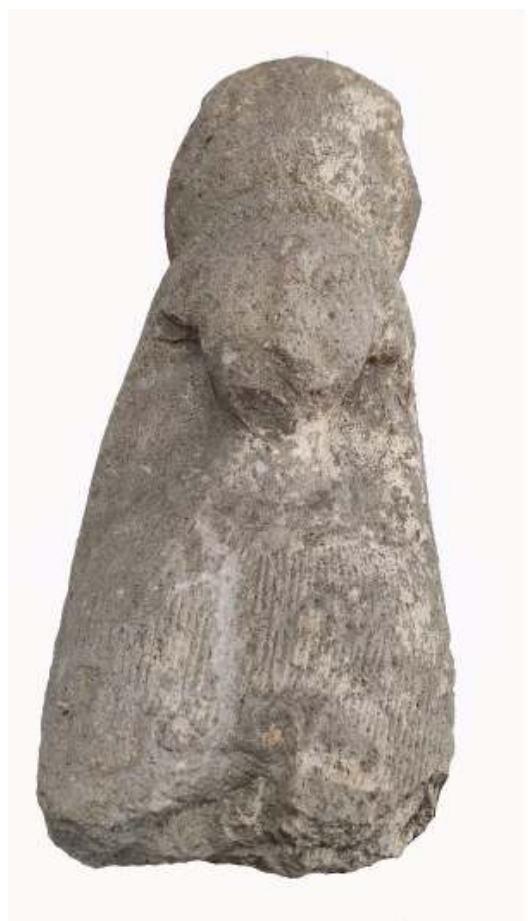

Figür 18: Alaplı'da bulunan Kybele heykeli.

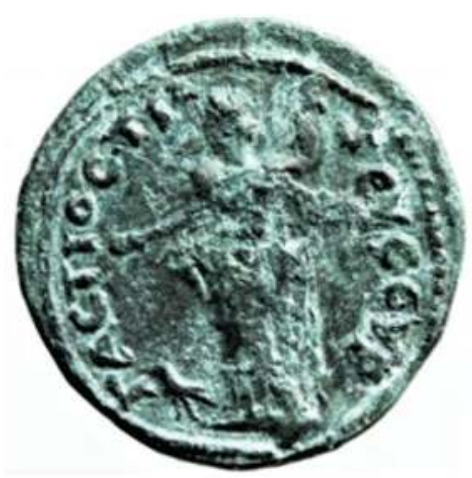

Figür 19: MS 3. yüzyıla tarihlendirilen, arka yüzünde

Zeus Syrgastios betimlemesi bulunan Tieion darbı bronz sikke. 